\title{
Using Water Allocation in Israel as a Proxy for Imputing the Value of Agricultural Amenities
}

\author{
Forthcoming 2018, Ecological Economics
}

Erez Yerushalmi*

January 2018

\begin{abstract}
This paper uses the water allocation economy in Israel as a proxy for imputing the value of agricultural amenities. A general equilibrium model is developed, and incorporates agricultural amenities as byproducts of agricultural production, water trade channels, and multiple water types. The premise is that until a decade ago, water policy in Israel was interlinked with agricultural land-use policy. Integrating a Monte-Carlo analysis, the model searches for a baseline minimum value of agricultural amenity that makes household, in the counterfactual scenario, indifferent between the administrative and market mechanisms. The minimum imputed value is around $109 \%$ agricultural output. The intuition is that the gains in economic welfare, from improved water use efficiency, are offset by the losses in social welfare due to a reduction in available agricultural amenities.
\end{abstract}

Key Words: agricultural amenities; administrative water allocation; water market; general equilibrium; Israel

JEL: D58, Q12, Q25, Q28, Q56, O21

*Birmingham City Business School, Erez.Yerushalmi@bcu.ac.uk 


\section{Highlights (3 to 5)}

- The agricultural sector creates amenities as a byproduct of production.

- The paper imputes the value of agricultural amenities in Israel.

- Quantifying the value of amenities is crucial for correctly valuing agricultural land.

- The method used is an economy-wide general equilibrium model.

- In Israel, the value of agricultural amenities is estimated at $109 \%$ the value of this sector's output.

\section{Acknowledgments}

My appreciation is extended to Christopher Adam, Peter Backus, Jonathan Cave, Alessandro Iaria, Clara Rübner Jørgensen, Alex Klein, Carlo Perroni, and Lei Zhang for discussion, and to three anonymous reviewers. 


\section{Introduction}

Agricultural activities produce benefits above and beyond the market value of production because they provide non-marketed amenities, such as ecosystem services and farm landscape. Amenities also include less tangible, non-use value (such as existence and bequest) (Oglethorpe and Miliadou, 2000), and other aspects of cultural, social and heritage preservation (Chan et al., 2012). ${ }^{1}$ They are typically not internalized by the sectors that create them, and are difficult to value in monetary terms (OECD, 2008).

The failure to account for the non-marketed value of agricultural amenities causes agricultural land to be undervalued and suboptimally allocated from society's point of view (OECD, 2005; Kan et al., 2009). For example, its loss to urbanization may be irreversible and costly to the well-being of society (defined as the economic and non-economic social aspects of welfare).

Therefore, it is highly important to measure the value of agricultural amenities in order to correctly assign property valuation, appraisals and taxation (Borchers et al., 2014), and design policies that support the agricultural sector through land subsidies, targeting and zoning (Engel et al., 2008). ${ }^{2}$ To address this issue, the aim of this article is to impute some of the non-marketed value of agricultural amenities.

A large body of empirical literature has already attempted to quantify the nonmarketed value of agricultural amenities using micro-level approaches. Examples include works on the external effects of farmland in the context of urban-rural land allocation (Borchers et al., 2014; Bergstrom and Ready, 2009; Bowker and Didychuk, 1994; Brunstad et al., 1999; Bergstrom et al., 1985; Bastian et al., 2002) and in Israel (Kan et al., 2009), on agricultural landscape value (Drake, 1992; Brunstad et al., 1999; Thiene and Tsur, 2013) and in Israel (Fleischer and Tsur, 2009), and on recreational value of open space in Israel (Fleischer and Tsur, 2003, 2000). As Chan et al. (2012) reports, fewer empirical studies have focused on the less tangible value. One relevant example is Becker et al. (2012) that exmine the non-use value in water management in Israel.

In this study, the contribution is twofold. It uses a macro-level approach, not previously applied for valuing amenities: an economy-wide, general equilibrium model

\footnotetext{
${ }^{1}$ The agricultural sector also produce negative externalities (e.g., non-point pollution, soil erosion, and others). This study considers the net amenity value (positive minus negative) because of the functional form used.

${ }^{2}$ A notable example is through payments for environmental services (PES) programs (e.g., SánchezAzofeifa et al., 2007; Muñoz-Piña et al., 2008)
} 
with Monte Carlo analysis. In addition, it uses the Israeli water economy as a proxy for the tangible and intangible amenity value that the public attributes to the agricultural sector. The model incorporates agricultural amenities as byproducts of agricultural production, and is based on the fact that when irrigation water is a limiting factor in agricultural production, water pricing and quotas are effective in directing social, political and environmental objectives (Thiene and Tsur, 2013).

Water can be allocated by an administrative mechanism, market-based mechanism, or a combination of both. ${ }^{3}$ This paper imputes the public's minimum willingness to accept an administrative mechanism, even though it creates distortions, because the rise in economic welfare generated by a hypothetical pure water market exactly offsets the lost social welfare from less available amenities. A pure water market improves economic welfare, when water inputs are used more efficiently, but reduces social welfare because the agricultural sector sells away its water inputs, reduces production, and therefore lowers the level of amenities available to households.

In Israel, the water allocation mechanism arises from a political arrangement of resources. The definition of agricultural amenities, therefore, covers a wide range of external benefits. de Groot et al. 2002 defines a topology of 23 ecosystem functions, which link with ecological, socio-cultural and economic value that make-up the total value of environmental goods. Hall et al. (2004) provide a review of the amenities that the public wants from agriculture and the countryside. In Israel, for example, beside the tangible amenities (e.g., food, landscape, and habitat) that the public attributes to the farming community, the public also views them as the "forefathers" of the State of Israel that gives them an intrinsic cultural, historical, and heritage value (Tal, 2007).

At the margin, this paper calibrates some of the agricultural amenities at around $109 \%$ its total economic output. However, the inframarginal value maybe much larger, suggesting that the administrative mechanism in Israel provides higher social-economic welfare compared to a pure water market. Furthermore, the findings indicate that desalination in Israel has been a cost-effective investment for alleviating the distortions made by the administrative allocation.

The imputed agricultural amenity is a partial value of its total because: (i) There are many other instruments besides water subsidies that support the agricultural sector (some examples are tariffs, anti-trust exemption, permits for foreign workers employment, etc) ${ }^{4}$, and using only one instrument underestimates the imputed amenities. (ii) The conservative parameters that are used overestimate the size of the

\footnotetext{
${ }^{3}$ Zhao et al. (2013) provide a clear discussion of the cost and benefits of each.

${ }^{4}$ OECD (2017) provides an extensive review.
} 
water market (and therefore more welfare is gained), but underestimate the weight of the agricultural amenities in households utility (thus again giving more weight to the benefits of the water market). (iii) The estimates relate only to the effect of irrigated lands, while amenities associated with rain-fed lands are ignored. Finally, (iv) Water management policies are based on political processes (e.g., influenced by interest groups), and not only on welfare maximization (Finkelshtain and Kislev, 1997); but this is beyond the scope of this paper. Therefore, a portion of the imputed amenity value may represent also these distortions.

To capture the welfare distortions from water policy in Israel, the model is calibrated to 2006 - a period of severe hydrological deficit. Using more recent data would be an ineffective way to impute the value of agricultural amenities because the water economy and agricultural land-use policy in Israel today are much less interlinked compared to how they were a decade or two ago. Water subsidies to the agricultural sector have been dramatically reduced, and land-use policy is now mainly managed through regulation and direct subsidies, and much less through the water economy. In addition, the low cost of desalination, and high volume of purified wastewater for irrigation, have removed the acute resource constraint to a point where the Israeli water authority has had to curb the over-supply of desalinated water while being urged to lower water prices. Though water remains an issue of political power in the Middle East (Beltrán and Kallis, 2018), the general debate on the shortfalls of the administrative mechanism have largely subsided. Water has thus become less of a limiting factor in agricultural production compared to 2006.

In what follows, Section 2 provides a background on the distortions of the administrative allocation in Israel. Section 3 introduces the economy-wide general equilibrium model with agricultural amenities. Section 4 presents the data of Israel. Section 5 summarizes the empirical results with some further discussion, and Section 6 concludes. An on-line supplementary appendix is also available with further details.

\section{Background on the distortions of the administra- tive water allocation in Israel}

Israel is an example of a country which has historically developed an administrative water allocation mechanism to promote social and political objectives, such as settlement and land policies, food security, and equitable consumption (Just et al., 1997; Menahem, 1998). Prices and quotas are set by the Israeli Water Authority (IWA) - a 
governmental agency. It is illegal to resell water quotas, though some intra-regional reallocation has been permitted. The agricultural sector was the main beneficiary and obtained water inputs at subsidized rates, but to a lesser extent today.

By mid-2000s, the distortions generated by the administrative water allocation mechanism in Israel were said to be responsible for a severe hydrological deficit in the country - a water crisis. Various parliamentary investigative committees and researchers concluded that for decades, water allocation had been mismanaged by oversubsidizing the agricultural sector and underfunding water supply development. The system was subjective, politicized, and included various governmental bodies responsible for different objectives (Davidovich, 2008). The formation of unsolicited black water markets in various regions was seen as an indication of these inefficiencies. ${ }^{5}$

Leading up to the water crisis, suggestions were made to introduce various types of market mechanisms so that water would be consumed by those that valued it most (for a review, see Parker and Tsur, 1997). However, this never materialized. After 2010, water tariffs were updated to reflect the full cost of supply, and reorganization was made, but overall, the administrative mechanism did not change. Instead, extensive investments were made to extend the supply of water. ${ }^{6}$

In conclusion, by mid-2000s, despite clear evidence of distortions, the administrative mechanism continued to be the favored allocation system. The next section elicits the household's preferences for agricultural amenities by constructing a hypothetical water market that is compared to the administrative mechanism.

\section{The model}

Applied, water-focused, computable general equilibrium (CGE) models have been developed to analyze many issues within the water economy (see detailed reviews by Dinar (2014) and Luckmann et al. (2014)). None, however, use CGE models to elicit the value of agricultural amenities.

Luckmann et al. $(2016,2014)$ and Baum et al. (2016) are recent examples of waterfocused CGE models that focus on Israel. They develop a highly detailed breakdown of water types, production sectors, and households, and simulate counterfactual sce-

\footnotetext{
${ }^{5}$ Black water markets have been investigated by the State Comptroller in 2012, and deliberated by the High Court of Justice (Bagatz) and the IWA. In March 2017, the IWA reaffirmed this practice as illegal unless authorized by the state.

${ }^{6}$ By 2018 , Israel operates five seawater desalination plants that provide more than two-thirds of the drinking water to households, and uses almost 90 percent of its purified wastewater for irrigation. See Haaretz (2014); Rinat (2016) for a general overview.
} 
narios that include drastic reductions in Israel's water supply, an increase in desalinated water, and alternative water pricing. Diao et al. (2008) have studied conjunctive ground and surface water policy in Morocco. These studies, however, analyze counterfactual scenarios within an administrative water allocation mechanism.

Only a handful of CGE studies introduce water markets that resembles this paper. For example, Hassan and Thurlow (2011) assess the effect of liberalizing regional and national irrigation water markets in South Africa; Diao and Roe (2003) link water allocation (administrative versus market) with protectionist trade policies in Morocco; and Gómez et al. (2004) assess the economic gains from introducing a water market in the Balearic Islands. Becker (1995) and Reznik et al. (2016) use partial equilibrium constrained maximization methods that introduce a water market in Israel, in a similar way to how water trade channels are set in this paper.

The common theme in all the above studies is that a market mechanism leads to economic gains because water inputs reach those users that value them most. This is also the case in this paper. The novel contribution here, however, is that agricultural production also creates a byproduct amenity that could be lost as a result of a water market, a point which has not been studied in similar CGE models. Here, I impute the value of agricultural amenities by weighing the additional benefits of a water market with the losses incurred by a reduction in agricultural amenities. The model thus shares some similarities with Thiene and Tsur (2013).

\subsection{Setup}

A water authority holds the property rights of water, and sets a framework of price discrimination, quotas, and prohibits water trade. Water users decide on the amount of water to buy within this framework. Households demand goods (including water) and also agricultural amenities. Firms supply goods, and agricultural firms also supply amenities as byproducts of their production ${ }^{7}$, which however, they do not internalize. In the counterfactual simulations, a hypothetical pure secondary water market is enabled. The model measures the volume of water that would be reshuffled between pairs of water users (relative to the baseline administrative allocation) and the price adjustments that clear the market.

To do this, I set up an Arrow-Debreu equilibrium as a mixed complementarity problem that is compactly expressed as $0 \leq x \perp y \geq 0 .{ }^{8}$ This allows for slack ac-

\footnotetext{
${ }^{7}$ Resembling Peterson et al. (2002); Vatn (2002).

${ }^{8} \mathrm{~A}$ complementarity constraint enforces that for variables $x$ and $y: x \cdot y=0, x \geq 0, y \geq 0$. Intuitively, this implies that either $x$ or $y$ must be 0 , or both.
} 
tivities that represent the opening and closing of water trade channels. The model is coded in GAMS ${ }^{9}$ using the MPSGE sub-language (Rutherford, 1995). Since the model contains a substantial number of standard mathematical equations, only the key equations linked to the water economy are presented. The online supplementary content includes further equations, model code, and calibration.

\subsection{Water authority, household, and production}

The water authority produces two types of water: potable water $W P$ and non-potable water $W N P$. In the baseline, household $h \in H$ and sector $i \in N$ are allocated water $\bar{W} P_{h}, W P_{i}, W \bar{N} P_{i} \in \bar{W}$ and pay different water prices $p_{W P, h}, p_{W P, i}, p_{W N P, i} \in p_{w}$. The objective of the water authority is full cost recovery, and therefore, the revenue from selling water equals the cost of labor, capital, and intermediate inputs (on the right hand side of equation 1 ), respectively:

$$
p_{W P, h} \bar{W} P_{h}+\sum_{i}\left(p_{W P, i} \bar{W} P_{i}+p_{W N P, i} W \bar{N} P_{i}\right)=p_{L} L_{w}+p_{K, w} K_{w}+\sum_{i} p_{i} X_{i w}
$$

A single household $h$ has a rational and locally non-satiated preference relation, with a continuous utility function $U(\cdot)$. Extending this model to multiple households is simple, but would require assumptions about how amenities are distributed, and how households are defined. ${ }^{10}$ The consumer's problem is a conventional demand system that has a two-level nested (hierarchical) constant returns to scale (CRS) structure, depicted in Figure 1. The lower nest is a Cobb-Douglas (CD) function, contained within the upper level constant elasticity of substitution (CES) function. (See supplementary appendix A.1 for further detail.)

Let $X_{i}$ represent consumption of final goods from sector $i$ with $p_{i}$ the consumer price. Furthermore, $X_{\text {amen }}$ in Figure 1 represents consumption of the amenity (discussed later in Section 3.4). $W P_{h}$ is the demand for potable water with price $p_{W P, h}$. Households are endowed with a supply of capital and labor $\bar{K}_{i}, \bar{K}_{w}, \bar{L}$, and note that capital is a sector specific input that represents a short-to-medium time horizon. ${ }^{11} \sigma_{h}$ is the substitution elasticity between potable water and the aggregate consumption

\footnotetext{
${ }^{9} \mathrm{http}: / /$ www.gams.com/

${ }^{10}$ For example, households could then refer to regions that control the water aquifers, neighboring countries, or income group. In this model, household refers to total private consumption in Israel.

${ }^{11}$ As Hertel (2002) discusses in detail, within a time frame of three to five years, land inputs are relatively rigid due to soil type, location, use-type, infrastructure, and legislative constraints. Capital becomes a highly rigid factor if land makes up a large portion of it. Furthermore, capital has quite different usages in various industries that takes time to adjust before being utilized for other purposes.
} 
Figure 1: The two-level nested utility function

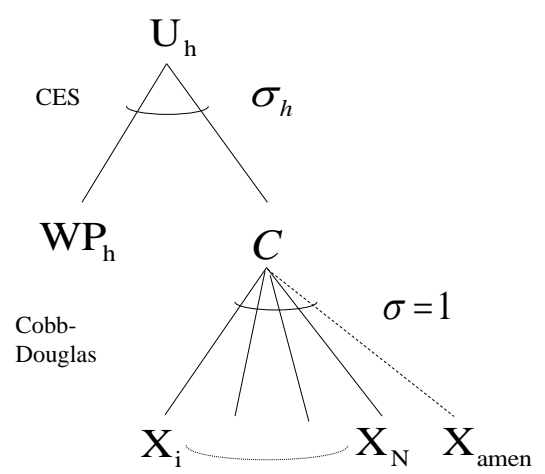

Note: The lowest level combines all final goods and amenities into an aggregate. In the top level, water input is combined with the final goods aggregate. $\sigma$ is the substitution elasticity at each level. See text for notation.
Figure 2: The four-level nested production function

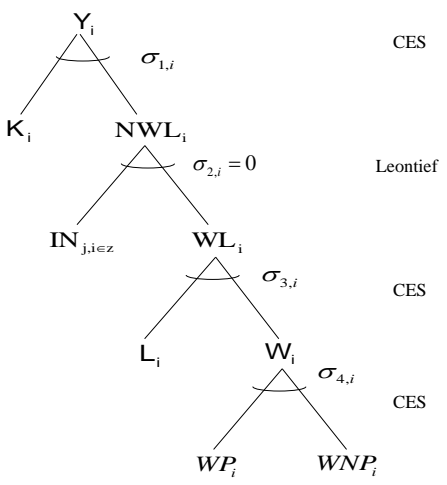

Note: The lowest level combines potable and non-potable water into a water aggregate. The third level adds labor inputs, the second adds intermediate goods, and finally, capital is added. See text for notation.

of final goods.

On the production side, sector $i$ produces a single final good $Y_{i}$, using a four-level nested CRS production function $Y_{i}=f_{i}\left(K_{i}, I N_{j i}, L_{i}, W P_{i}, W N P_{i}\right)$ that requires capital, intermediate inputs, labor and potable and non-potable water inputs, respectively. Prices are defined as $p_{K, i}, p_{j}, p_{L}, p_{W P, i}, p_{W N P, i} \in p$, respectively. The production function is illustrated in Figure 2, with $\sigma_{1}$ to $\sigma_{4}$ the substitution elasticity at each nested level. ${ }^{12}$

At the baseline, prices are determined at the levels which clear output and factor markets, so that $\sum_{i} L=\bar{L}, K_{i}=\bar{K}_{i}, K_{w}=\bar{K}_{w}, W N P_{i}=W \bar{N} P_{i}$, and output equals final demands $Y_{i}=X_{i}+X_{i w}+\sum_{j} I N_{i j}$. Furthermore, as long as water trade is prohibited, the market clearing condition for Potable water is

$$
\begin{gathered}
W P_{i}=\bar{W} P_{i} \\
W P_{h}=W \bar{W} P_{h} \\
p_{W, i} \neq p_{W, j} \neq p_{W, h}
\end{gathered}
$$

which, however, changes once water trade is enabled.

The water authority sets increasing block tariffs (IBT) that are differentiated among water users. Users are not constrained by the total amount of water they choose to purchase, but they pay higher charges within the IBT framework. This

\footnotetext{
${ }^{12}$ This structure eases the calibration of the substitution elasticities (reported in appendix B).
} 
means that the marginal values of water $(M V W)$ equal the real water prices: ${ }^{13}$

$$
\begin{aligned}
M V W_{i} & =\frac{\partial Y_{i}}{\partial W P_{i}} \leq \frac{p_{W P, i}}{p_{i}} \quad \perp \quad W P_{i} \geq 0, \quad \forall i \\
M V W_{h} & =\frac{\partial U}{\partial W P_{h}} \leq \frac{p_{W P, h}}{p_{U}} \quad \perp W P_{h} \geq 0
\end{aligned}
$$

Note that equations (3) and (4) are written as full complementarity problems whereby as long as the MVW equals the real cost of the water input, demand for water is positive. Otherwise, if the real cost of water is greater than its MVW, demand for water is zero. Finally, based on the calibration stage, each water user has a different marginal value of water (MVW) such that

$$
M V W_{i} \neq M V W_{j} \neq M V W_{h}
$$

\subsection{Explicit water trade channels}

This next section explains how water trade channels are set, and how the model estimates the volume of water that is reshuffled in a secondary water market, once trade is allowed in the counterfactual scenario.

As an example, assume that in the baseline with no water trade, sector 2's marginal value of water is higher than of sector 1 . Following from equation (3), $\frac{p_{W P, 1}}{p_{1}}=M V W_{1}<$ $M V W_{2}=\frac{p_{W P, 2}}{p_{2}}$. If water trade would be allowed, sector 2 would prefer to buy some additional water from sector 1 (and sector 1 prefers to sell), up to a point where $M V W_{1}=M V W_{2}$.

In the model, water users can be buyers or sellers, and having $M=N+H$ water users (i.e., $N$ sectors and $H$ households) leads to $M^{2}$ trade configurations. Furthermore, define $\psi$ to be the pre-trade relative marginal value of water. If user $b \in M$ is a buyer, and user $s \in M$ is a seller, a possible trade channel is when $\frac{M V W_{b}}{M V W_{s}}=\psi_{s b}>1$; otherwise, it cannot be a possible trade channel. This is summarized by

$$
\frac{M V W_{b}}{M V W_{s}}= \begin{cases}\psi_{s b}>1 & \text { possible trade channel } \\ \psi_{s b} \leq 1 & \text { no trade }\end{cases}
$$

These conditions, therefore, limit the number of configurations to only $T=\frac{M(M-1)}{2}$ possible trade channels, with $t \in T$ being one specific channel. (Table 2 will provide a

\footnotetext{
${ }^{13}$ The exception is at the kinks between two adjacent tariff blocks (Bar-Shira et al., 2006). To deal with this, I will use an average $M V W$ across all agricultural sectors which eliminates the kinks.
} 
concrete numerical example of equation 5.)

Thus, when water trade is enabled in a secondary water market, the units of water for each channel, $\gamma_{t}$, that are transferred between seller $s$ and buyer $b$ are measured by

$$
0 \leq \gamma_{t} \perp p_{W P, s, t}-(1-\epsilon) p_{W P, b, t} \geq 0, \quad \forall t
$$

with $p_{W P, s, t}$ and $p_{W P, b, t}$ being the real water market prices for the seller and buyer, respectively. ${ }^{14}$ For computational purposes, $\epsilon \rightarrow 0$ is a small number to 'help' the solver with slack activities, thus avoiding the problem of infinite solutions, i.e., a degenerate model. ${ }^{15}$

There are various combinations (scenarios) of activating and deactivating water trade channels that can be controlled, e.g., activating each channel separately, or all together. Therefore, each of the $t \in T$ channels has a binary action (designed by the scenario); active or not-active, $\{\mathcal{A}, \mathcal{N} \mathcal{A}\} \in$ Action. There are $\left\{t_{\mathcal{A}}, t_{\mathcal{N}_{\mathcal{A}}}\right\} \in T$ channels, $\left\{i_{\mathcal{A}}, i_{\mathcal{N}_{\mathcal{A}}}\right\} \in N$ firms, and $\left\{h_{\mathcal{A}}, h_{\mathcal{N}_{\mathcal{A}}}\right\} \in H$ households, that are active or not-active, respectively.

When Equation (6) is enabled for $t_{\mathcal{A}}$, water trade is allowed for a pair of users, and water units, $\gamma_{t_{\mathcal{A}}}>0$, are exchanged up to the point where sellers and buyers have equalized water prices, $p_{W, s, t}=(1-\epsilon) p_{W, b, t}$. If, however, the unit water price of a seller is higher than the unit price of a buyer, $p_{W, s, t_{\mathcal{A}}}>(1-\epsilon) p_{W, b, t_{\mathcal{A}}}$ (a strict inequality), the activity goes slack, $\gamma_{t_{\mathcal{A}}}=0$, and there is no trade.

Enabling water trade, in the counterfactual scenario, updates the potable water market clearing condition from Equation (2):

$$
\begin{gathered}
W P_{h_{\mathcal{A}}}+\sum_{i_{\mathcal{A}}} W P_{i_{\mathcal{A}}}=\bar{W} P_{h_{\mathcal{A}}}+\sum_{i_{\mathcal{A}}} W P_{i_{\mathcal{A}}} \\
p_{W P, i_{\mathcal{A}}}=p_{W P, j_{\mathcal{A}}}=p_{W P, h_{\mathcal{A}}} \\
W P_{i_{\mathcal{N A}}}=W P_{i_{\mathcal{N A}}} \\
W P_{h_{\mathcal{N A}}}=W P_{h_{\mathcal{N A}}} \\
p_{W, i_{\mathcal{N A}}} \neq p_{W, j_{\mathcal{N} \mathcal{A}}} \neq p_{W, h_{\mathcal{N A}}}
\end{gathered}
$$

whereby for the active water trade channels, water charges are equalized, while other non-active channels still view water as a sector specific input.

\footnotetext{
${ }^{14}$ In the calibrated baseline, total costs are set to unity, so water prices are in real terms.

${ }^{15}$ This insures that when multiple $t$ channels are opened (active), only net transfers of water is considered. For example, a case of infinite solutions is when a first user sells to the second, the second sells to the third, but the first also sells to the third. By adding $\epsilon$, the solution is limited to one case where, for example, the first sells to the second and to the third, while deactivating the second selling to the third.
} 


\subsection{Modeling agricultural amenities}

Next, I explain how agricultural amenities are produced by the agricultural sector and consumed by the representative household.

Focusing again on production, the agricultural amenity $X_{\text {amen }}$ is created as a byproduct in fixed proportion to agricultural production $Y_{a g r \in i}$ (i.e., a Leontief technology), and has shadow price $p_{a m e n}$. The sector does not internalize the amenities it generates because a fictive tax rate on the amenities, set to $\tau_{\text {amen }}=100 \%$, nullifies any revenues from the amenities.

Omitting index $a g r$, the profit maximization problem for the agricultural sector, is

$$
\begin{aligned}
\operatorname{Max} \pi & =\underbrace{\left(1-\tau_{a m e n}\right) p_{a m e n} X_{a m e n}}_{=0}+p Y-\operatorname{Cost}(\cdot) \\
\text { s.t. } Y & \geq \min \left\{Y, \delta X_{a m e n}\right\} \\
Y & \geq f\left(K, I N_{j}, L, W P, W N P\right)
\end{aligned}
$$

with $\delta$ the calibrated parameter for the agricultural amenities (i.e., amenities are omitted when $\delta=0$, and otherwise when above zero, $\delta>0$ ).

On the demand side, the household consumes goods (as previously discussed), but also an agricultural amenity. The fictive tax revenue, $p_{a m e n} X_{a m e n}$, is directly transferred to the household as an endowment, so that they endogenously consume as much amenity as is provided to them (see equation A.1 in the supplementary appendix). ${ }^{16}$ The substitution elasticity in utility between the amenities and other goods is unity, which is an upper-bound at a macroeconomic level. A lower value will raise the imputed amenities. ${ }^{17}$

Two issues to note regarding the functional form that generates the amenity: First, the agricultural sector also produces negative externalities that lower welfare (e.g., non-point pollution, soil erosion, nutrient runoff, greenhouse gases and others). Since water policy was set while considering both positive and negative amenities, the amenity imputed here represents the net amenity value (positive minus negative). Using a CRS function maintains this in the counterfactual scenarios. Second, this fixed transformation function implies a zero transformation elasticity between the agricultural commodity and the amenity, making it a lower-bound value. ${ }^{18}$

\footnotetext{
${ }^{16}$ Note that a counterpart of $\delta$ is $\theta_{\text {amen }}$, the share exponent of the amenity in utility, which is clearly defined in supplementary appendix A.1. When $\theta_{\text {amen }}=0$, amenities are omitted from the baseline calibration, but present when $\theta_{\text {amen }}>0$.

${ }^{17}$ To my knowledge, there are no known values for these elasticities.

${ }^{18}$ Alternatively, using a constant elasticity of transformation function with higher parameter would
} 
Finally, it is important to realize that in this setup, different baseline calibrations of the amenities will not affect the counterfactual general equilibrium outcomes of the marketed commodities. There is only one counterfactual solution for the goods markets because $(i)$ firms produce according to their profit maximization problem without internalizing the amenities, and (ii) households consume as many non-marketed amenities as provided to them. In this simple setup, the only difference between a model with and without agricultural amenities will be the interpretation of welfare.

\subsection{Closure rules for the government and international trade}

Following standard applications in computable general equilibrium (CGE) models, the government receives income from taxes and tariffs, and receives net-funds from domestic households and the rest of the world. The government saves a fixed amount of its income, and provides the public services by purchasing commodities in fixed proportions. In counterfactual experiments, the closure rule is to fix the level of public provision to the baseline level, by endogenously transferring net-income to (from) the household so that the government maintains a balanced budget. These assumptions avoid the problem of a 'free gift' which would create a problem to interpret welfare.

In terms of international trade, the model is a small open economy that cannot affect world prices. In this static model, the closure rule is to fix the balance of payments (i.e., export and import prices quoted in foreign currency are exogenous) because it would be difficult to interpret welfare when the current account deficit rises, for example, acting as a 'free gift' (Hosoe et al., 2010). In the long-run, the current account should balance on average.

\section{Calibrating the model to Israel}

The model is calibrated to Israel's 2006 social accounting matrix (SAM), which I derive from the 2006 Use and Supply tables of 205 industries and the 2006 Satellite Account of Water in Israel (Israeli Central Bureau of Statistics - CBS) ${ }^{19}$ GDP was 154.5 billion (bln) US Dollars (\$), and household consumption was $\$ 82.1$ bln. ${ }^{20}$

The data is aggregated to four main water users, to simplify the model and (mainly) because the overall results would not significantly change had they been further dis-

only raise the imputed amenity value.

${ }^{19}$ The SAM is documented in supplementary appendix C.

${ }^{20}$ All data from CBS are provided in NIS. For convenience, these are converted to $\$$, based on the Bank of Israel annual average exchange rate in 2006 of $\mathrm{NIS} / \$=4.4565$. 
Table 1: Key water figures in Israel (2006)

\begin{tabular}{|c|c|c|c|c|c|c|c|}
\hline \multirow[b]{2}{*}{ User } & \multicolumn{4}{|c|}{ Potable Water } & \multicolumn{3}{|c|}{ Non-Potable Water } \\
\hline & $\begin{array}{r}\text { Mil. } \\
\text { Cubic } \\
\text { Meters } \\
(1)\end{array}$ & $\begin{array}{r}\% \text { of } \\
\text { Total } \\
(2)\end{array}$ & $\begin{array}{r}\text { Expenditure } \\
\text { (mil. \$) } \\
\text { (3) }\end{array}$ & $\begin{array}{r}\text { Avrg MVW } \\
(\$ / C M) \\
(4)\end{array}$ & $\begin{array}{r}\text { Mil. } \\
\text { Cubic } \\
\text { Meters } \\
(5)\end{array}$ & $\begin{array}{r}\% \text { of } \\
\text { Total } \\
(6)\end{array}$ & $\begin{array}{r}\text { Expenditure } \\
\text { (mil. \$) } \\
\text { (7) }\end{array}$ \\
\hline Agriculture & 513.3 & 38 & 124 & 0.241 & 587.5 & 94 & 129 \\
\hline Manufacturing & 71.6 & 5 & 47 & 0.660 & 30 & 5 & 10 \\
\hline Services & 207.7 & 16 & 132 & 0.638 & 5.5 & 1 & 3 \\
\hline Household & 543.5 & 41 & 503 & 0.926 & 0 & 0 & 0 \\
\hline $\begin{array}{l}\text { Total } \\
\% \text { Total Water }\end{array}$ & 1,336.1 & $\begin{array}{r}100 \% \\
68 \%\end{array}$ & 807 & & 623 & $\begin{array}{r}100 \% \\
32 \%\end{array}$ & 142 \\
\hline Export & 102.2 & & 35 & & & & 0 \\
\hline Grand Total & $1,438.3$ & & 984 & & 623 & & 142 \\
\hline
\end{tabular}

Source: CBS and CBS Water Satellite Account; Bank of Israel: annual average exchange rate NIS $/ \$=4.4565$.

Table 2: Water trade channels (relative MVW, 2006)

\begin{tabular}{rlcccc}
\cline { 2 - 5 } Seller $n \in M$ & \multicolumn{5}{c}{ Buyer $m \in M$} \\
Agricultural & Manufacturing & Services & Household \\
\cline { 2 - 6 } & Agricultural & 1 & $\mathbf{2 . 7 3 6}$ & $\mathbf{2 . 6 4 3}$ & $\mathbf{3 . 8 3 8}$ \\
& Manufacturing & 0.365 & 1 & 0.966 & $\mathbf{1 . 4 0 3}$ \\
& Service & 0.378 & $\mathbf{1 . 0 3 5}$ & 1 & $\mathbf{1 . 4 5 2}$ \\
& Household & 0.261 & 0.713 & 0.689 & 1
\end{tabular}

Note: The table summarizes the ratio of seller/buyer water marginal value. Bold values are the possible water trade channels.

aggregated. Table 1 provides a breakdown of water consumption. In 2006, 1336 million cubic meters (MCM) of potable water was consumed: $38 \%$ by the agricultural sector, $41 \%$ by households, and the remainder by manufacturing and service sectors. 623 MCM was non-potable water (salinized, contaminated, sewage effluents, flood, and brackish water) mainly consumed by the agricultural sector.

The average MVW for each water user is obtained by dividing their water expenditure by water consumption (see column 4 in Table 1). Then, water trade channels are set in Table 2 by dividing the MVW for each pair of users from Table 1 . In our case, having four water users leads to sixteen water trade configurations. Following from equation (5) in which $\psi_{s b}>1$ (i.e., when the relative MVW is greater than one), there are six possible channels (marked in bold) that indicate who would be the seller and buyer in each channel. For example, in 2006, the household valued water by 
Table 3: Parameters used in the model

\begin{tabular}{|c|c|c|c|c|}
\hline & \multicolumn{3}{|c|}{ (1) } & \multirow[b]{3}{*}{$\eta \sim \operatorname{Beta}(\alpha, \beta)$} \\
\hline & Lower & Mid & Upper & \\
\hline \multicolumn{4}{|c|}{ Output supply price elasticities, $\eta$} & \\
\hline Agriculture & 0.4 & 0.8 & 1.2 & $(3,3)$ \\
\hline Manufacturing & 1 & 3 & 5 & $(6,6)$ \\
\hline Services & 1 & 3 & 5 & $(6,6)$ \\
\hline \multicolumn{4}{|c|}{ Water demand price elasticities, $\epsilon$} & $\epsilon \sim \operatorname{Beta}(\alpha, \beta)$ \\
\hline Agriculture & -0.1 & -0.7 & -2 & $(10,15)$ \\
\hline Manufacturing & -0.1 & -0.7 & -2 & $(10,15)$ \\
\hline Services & -0.01 & -0.1 & -1 & $(1,7)$ \\
\hline Household & -0.01 & -0.1 & -1 & $(1,7)$ \\
\hline \multicolumn{5}{|c|}{ Potable/Non-potable substitution Elasticity, $\sigma_{4}$} \\
\hline Agriculture & & 1.1 & & \\
\hline Manufacturing & & 0.2 & & \\
\hline
\end{tabular}

Note: Column 1 are the range for supply-price and demand-price elasticities. These values, with the cost shares from the SAM, calibrate the substitution elasticities between inputs for utility and production. Column 2 are the PDFs for the beta distributions used in the Monte Carlo simulations.

approximately 3.838 times that of the agricultural sector, ${ }^{21}$ and therefore would buy from the agricultural sector.

\section{Other parameters}

In Table 3, column 1 summarizes the output supply and water demand price elasticities used in the model. Conservative values were chosen that overestimate the value of the water market. Following a method outlined by Rutherford (2002) and Shoven and Whalley (1992), which generalize any nested-structure that combines key elasticities with the cost-shares from the SAM, these parameters approximate the unknown substitution elasticities in the production and utility functions. ${ }^{22}$ Column 2 provides the probability density function (PDF) for the beta distribution that generate the Monte-Carlo simulations, with the lower and upper parameters from column $1 .^{23}$

\footnotetext{
${ }^{21}$ Divide households MVW 0.926 by Agriculture MVW 0.241. Numbers are slightly different from those reported in the table due to rounding error.

${ }^{22}$ Supplementary appendix B provides a detailed literature review of the elasticities and the approximation method.

${ }^{23}$ See the supplementary appendix D for further detail on the Monte Carlo method.
} 


\section{Results}

Results are reported in two stages: (i) to provide context for why economic welfare rises in this model, the main findings generated from a water market are reported. At this stage, agricultural amenities are ignored from the initial calibration, as in most economy-wide models that are based on national accounts data. (ii) I then impute the minimum value of agricultural amenities that would make households indifferent between the administrative and pure market mechanisms. This social aspects of welfare brings us partially closer towards well-being.

\subsection{A water market without agricultural amenities}

Table 4 reports the results of a water market ignoring agricultural amenities. ${ }^{24}$ When all water trade channels are open, $113 \mathrm{MCM}$ of potable water would be traded within the secondary water market (see column 1 ), which is $8.4 \%$ of the total potable supplied in 2006. Although all six water trade channels are open, the agricultural sector is the only net-seller, of which manufacturing buys $37 \mathrm{MCM}$, services buys $15 \mathrm{MCM}$, and household buys 61 MCM.

The water market clears when water prices change sufficiently to allow the marginal value of water to equalize for all users. Water price rises by $33.8 \%$ for agriculture, and falls for the other users (see column 4). The market clearing potable water price would be $0.323 \$ / M C$ (not reported but easily verified).

As expected, welfare rises because by enabling water trade, water inputs are put to better use, and the production possibility frontier of the economy moves outwards. The model computes a welfare gain of $\$ 27.8 \mathrm{mln}$ (million, real 2006 prices) in terms of equivalent variation in household expenditure (column 3). ${ }^{25}$ This is a small welfare gain of $0.034 \%$ (relative to the baseline) simply because the water economy in Israel is only around $0.4 \%$ of GDP; The share of potable water inputs from total input cost was only $0.4 \%$ of household's disposable income, $2.2 \%$ in the agricultural sector, and less than $0.1 \%$ for manufacturing and service sectors.

Furthermore, as expected, agricultural production falls by around $0.5 \%$, as it sells water to the other users. Manufacturing sectors marginally raise production and service sectors marginally lower it $(0.05 \%$ and $-0.004 \%$, respectively). Prices of final goods rise mainly because household income rises, which raises demand for all goods.

\footnotetext{
${ }^{24}$ Detailed results and the GAMS model are available from the author upon request.

${ }^{25}$ I do not report on changes to government spending, investments, and net exports because, as previously explained, they were deliberately held constant (in real terms) in the model.
} 
Table 4: Model results (2006 prices, change from baseline)

\begin{tabular}{|c|c|c|c|c|c|}
\hline & \multirow[b]{2}{*}{$\begin{array}{r}\text { Water } \\
\text { MCM } \\
(1)\end{array}$} & \multirow{2}{*}{$\begin{array}{c}\begin{array}{c}\% \text { of } \\
\text { total }\end{array} \\
\text { potable } \\
(2)\end{array}$} & \multirow{2}{*}{$\begin{array}{r}\text { Welfare } \\
\text { gains } \\
\$ \text { mln } \\
(3)\end{array}$} & \multicolumn{2}{|c|}{$\%$ Change in water prices } \\
\hline & & & & $\begin{array}{r}\text { Potable } \\
(4)\end{array}$ & $\begin{array}{c}\text { Non- } \\
\text { potable } \\
(5)\end{array}$ \\
\hline \multicolumn{3}{|c|}{$\begin{array}{l}\text { All water trade channels open } \\
\text { (of which) }\end{array}$} & \multirow[t]{2}{*}{27.8} & & \multirow[t]{2}{*}{8.9} \\
\hline Agriculture sell & 113 & 8.4 & & 33.8 & \\
\hline Manufacturing buy & 37 & 2.7 & & -51.1 & \\
\hline Services buy & 15 & 1.1 & & -49.4 & \\
\hline Household buy & 61 & 4.6 & & -65.1 & \\
\hline Total supplied & 1336 & & & & \\
\hline
\end{tabular}

Column 1 is the quantity of water traded. Column 2 is the percent of water traded from the total potable water supply (1336 MCM). Column 3 is the welfare gains in \$US Million. Columns 4 and 5 are percent change of potable and non-potable water price from the initial allocation.

\section{Monte Carlo simulation without amenities}

Comprehensive sensitivity testing was conducted to understand how the model behaves and to assess its reliability. Table 3 summarizes the upper and lower values tested, which are well-above and below the accepted values reported in other studies. The direction of the results were as expected. Using these extreme, unlikely, point-estimates in a mechanical way, I find the potential secondary water market to be at a range of 14.4 to $367.2 \mathrm{MCM}$. The largest effect comes from changing the water demand elasticities. Output supply price elasticity has a very minor role, mainly because potable water inputs are a small share of total input costs. Furthermore, experimenting with capital as a fully tradeable input increases the size of the secondary water market, but by a negligible measure.

I also use a Monte Carlo simulation to randomly generate a group of elasticity parameters that jointly enter into the model. This is a more sophisticated way to capture some of the notional characteristics provided by empirical literature (i.e., a prior), even though the choice of PDF may be criticized for being subjective. However, I have tried to make the best judgment based on available literature to counter this. The model is then executed 30,000 times and results are collected and analyzed. ${ }^{26}$

Figure 3 plots the sample distribution of the potential secondary water market. The sample average is $127 \mathrm{MCM}$, which is equivalent to around $9.5 \%$ of the total potable water supply (i.e., $1336 \mathrm{MCM}$ ), with a standard deviation of $43 \mathrm{MCM}$. The 99\%

\footnotetext{
${ }^{26}$ Supplementary content D provides further explanation and plots the sampled PDF.
} 
Figure 3: The potential size of water trade (PDF of the Monte Carlo simulation, MCM)

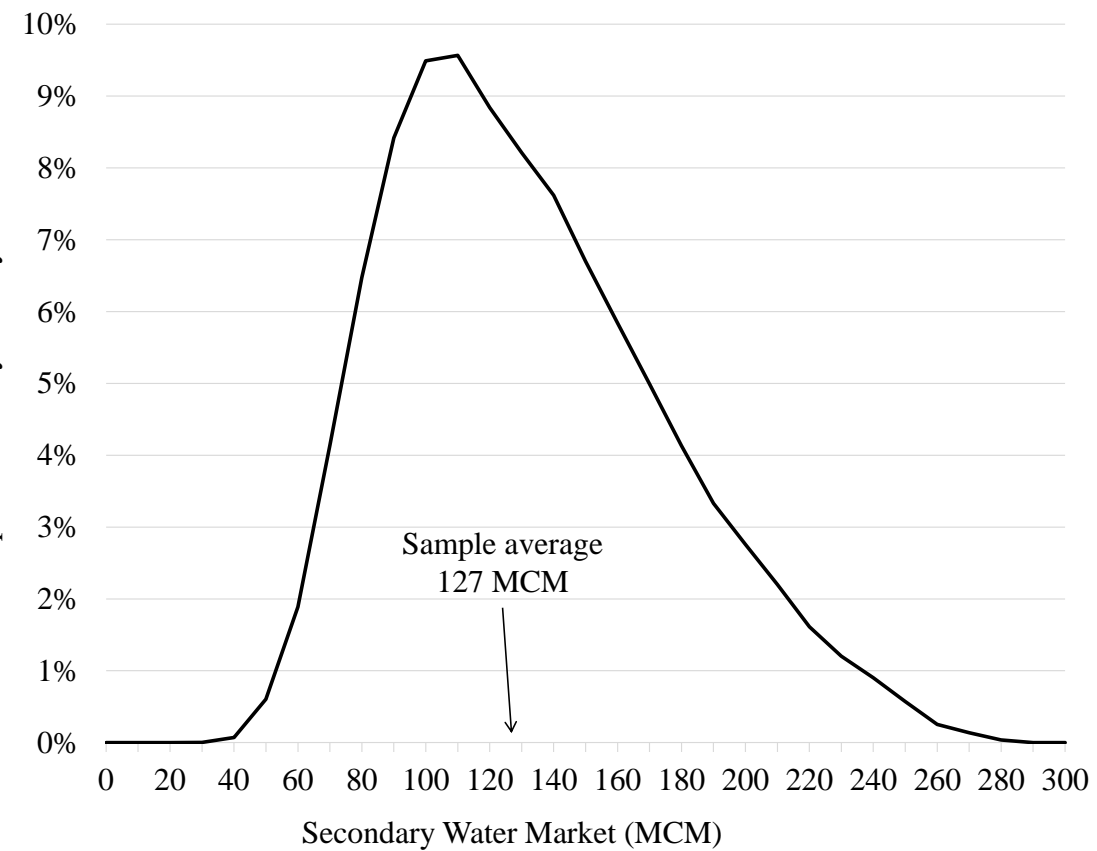

Note: The sample average volume of water traded in the secondary water market is 127 MCM, with a standard deviation of 43 MCM. The 99\% large sample confidence interval falls between [126.3, 127.5] MCM. Average welfare gain is $\$ 31.6 \mathrm{mln}$.

large sample confidence interval falls between $[126.3,127.5] \mathrm{MCM} .{ }^{27}$ At this confidence interval, the welfare gain from introducing a water market is around $\$ 31.6$ million.

To put this into perspective, an average desalination plant produces $125 \mathrm{MCM}$ of water per year, at a sunk-cost investment of less than $\$ 500 \mathrm{mln}$. The cheapest operating cost is 0.5 \$/CM (Shemer and Semiat, 2017), i.e., an average cost of around $\$ 63 \mathrm{mln}$ at full production per year. This is a cost-effective investment for alleviating water stress, especially when considering the non-marketed value of agricultural amenities, discussed in the next section.

In a related analysis, Becker et al. (2012) compare two water management policies: (i) Divert water from the Sea of Galilee ${ }^{28}$ towards agricultural irrigation and household use, or (ii) Desalinate the same amount. They show that ranking their cost-effectiveness depends heavily on whether the non-marketed value are included. Option 1 is preferable when considering only the economic value, but option 2 is preferable when the non-marketed value are also included. This is discussed next.

\footnotetext{
${ }^{27}$ For a sample size $n$, the Central Limit Theorem states that the studentized mean is approximately a standard normal: $\frac{\bar{x}-\mu}{s / \sqrt{n}} \approx N(0,1)$.

${ }^{28}$ The Sea of Galilee is the largest sweet water lake in the north of Israel. Water is pumped out and supplied to the south of Israel by the national water canal.
} 
Figure 4: The negative relationship between the calibrated amenities and welfare change

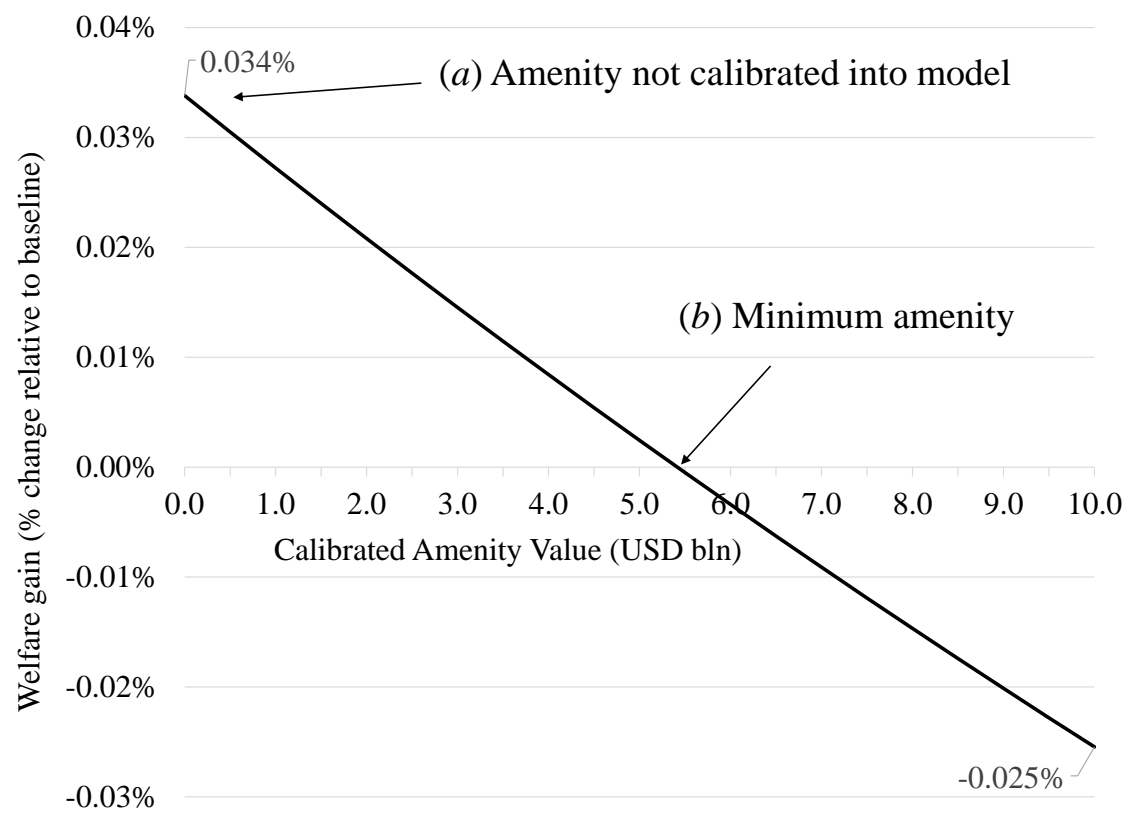

Note: An imputed value of amenities of $\$ 5.3 \mathrm{bln}$, in the baseline, would make the administrative and market mechanism indifferent in the counterfactual scenario.

\subsection{Imputing the value of agricultural amenities}

The value of agricultural amenities in monetary terms is unknown. The previous section reported only the economic welfare based on marketed goods, as in traditional models. I now extend the definition of welfare to include some of the social value of non-marketed goods.

To impute the value of agricultural amenities, I raise its baseline value from 0 to $\$ 10 \mathrm{bln}$, and assess the change in social-economic welfare in the counterfactual scenario (relative to the baseline). Figure 4 summarizes the results. Remember that in all cases, commodity markets are identical to those reported in Section 5.1 (i.e., changes to production, prices, water trade and water prices are the same as with no amenity). Recall that as long as the fictive tax on the amenities is $100 \%$, the agricultural sector does not internalize the amenity it creates, and the household consumes all that is transferred to it. The baseline value of the agricultural amenity is therefore irrelevant. What has changed is the definition of welfare (that moves closer towards well-being).

Point $a$ in Figure 4 shows that omitting the amenities from the calibration would raise welfare by $0.034 \%$ (as previously reported). However, as the baseline value of amenities is raised, the increase in welfare falls in the counterfactual scenarios. Agri- 
Figure 5: The value of amenities required for indifference between administrative and market allocation (PDF of the Monte Carlo simulation)

$35 \%$

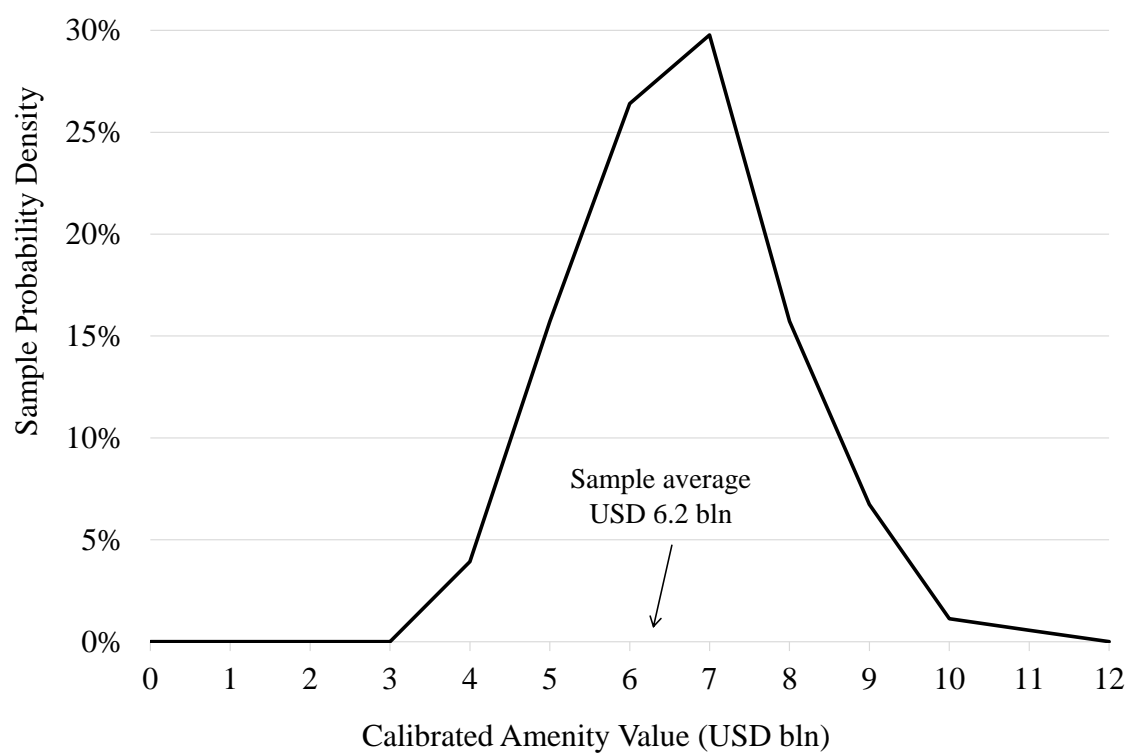

Note: The $99 \%$ large sample confidence intervals falls between $\$[5.9,6.4] \mathrm{bln}$. The figures show when households are indifferent between the market and administrative mechanisms, i.e., when the sample welfare change is zero.

cultural firms do not internalize the byproduct amenities that they create and lower production as they resell water inputs. The supply of available amenities is therefore reduced, which lowers households welfare. For Israel 2006, I find that the minimum imputed value that would make the public willing to accept the administrative mechanism, despite its distortions, is around $\$ 5.35$ bln (point $b$, where the y-axis crosses zero in Figure 4); A calibrated amenity value above point $b$ would lower welfare compared to the administrative mechanism.

\section{Monte Carlo simulation including amenities and discussion}

I now use the Monte Carlo method, as before, but also randomly select a value of the amenities from a uniform PDF from 0 to $\$ 12 \mathrm{bln}$. A uniform PDF is chosen due to a lack of reasonable prior, which gives equal probability to all randomly selected values of the amenity. The model is executed 100,000 times, and all results close to zero social-economic welfare change are analyzed (i.e., 178 occasions of 100,000 that fall between $-0.00005 \% \leq 0 \leq 0.00005 \%$ ). Figure 5 plots the sample distribution, which has an average of $\$ 6.2 \mathrm{bln}$, with a standard deviation of $\$ 1.32 \mathrm{bln}$. The $99 \%$ confidence interval of the minimum value falls between $\$[5.9,6.4] \mathrm{bln}$.

At the margin, this is around $109 \%$ of the agricultural output, or equivalent to $4 \%$ 
Table 5: Components of social welfare (bln $\$, 2006)$

\begin{tabular}{lrr}
\hline & bln $\$$ & Amenities as \% of \\
\hline Imputed value of agricultural amenities $^{a}$ & 6.2 & \\
\hline Agricultural output $^{b}$ & 5.7 & $109 \%$ \\
Private consumption $^{b}$ & 82.1 & $7.5 \%$ \\
$\mathrm{GDP}^{b}$ & 154.5 & $4.0 \%$ \\
\hline
\end{tabular}

Source: ${ }^{a}$ Model results, ${ }^{b}$ CBS Israel (Use table 2006)

of the total 2006 GDP (summarized in Table 5). The inframarginal value of agricultural amenities is much higher, which suggests that a rise in economic welfare by a pure water market would not be sufficient to cover for the losses in social welfare. This is not to say that a market-based mechanism, which correctly incorporates the value of amenities, cannot provide similar or even better results (e.g., by using direct farmer subsidies, or other means). Agricultural amenities would then need to be appropriately "commodified", which however, might not be feasible or not appropriate in the first place, as discussed by Kosoy and Corbera (2010). ${ }^{29}$

Defining the net-social agricultural output as the sum of the economic agricultural output plus its social output (i.e., the amenities), the imputed value of amenities is roughly $52 \%$ of net-social output. In another study in Israel, Kan et al. (2009) evaluate the changes to the net-social benefit from an intra-agricultural land reallocation among crops. They calibrate their model based on a ratio of $33 \%$, which they extrapolate from an amenity-value function derived by Fleischer and Tsur (2009). The calibration is possibly smaller than my result because Kan et al. only cover vegetative agriculture, landscape value, and a portion of the Israeli population (i.e., the amenity value rises with population size). My result, therefore, could be used by studies (similar to Kan et al.) as an alternative amenity-value function.

To compare with other studies, the amenity value is divided by the area of agricultural land. CBS Israel reports that agricultural cultivated irrigated land, in 2006, was 183.6 thousand hectares (ha), from a total of 283 thousand ha that also included unirrigated land. The newer National Topographical Database (Bental) estimates it to be around 418.7 thousand ha. ${ }^{30}$ This means that based on my results, the amenity value per hectare is in a range of $\$ /$ ha 14.8 to 33.8 thousand. This is similar in size to Thiene and Tsur (2013) who have used a hedonic price method to estimate the farm

\footnotetext{
${ }^{29}$ Kosoy and Corbera (2010) provide an excellent review of the dangers of over-commodifying environmental amenities, which they call commodity fetishism.

${ }^{30}$ The discrepancy is explained by the methods: CBS collects and analyses survey data (e.g., foreign agricultural workers, water usage, farm insurance, and others), thus obtaining a partial picture. Bental, on the other hand, is based on areal photos that show the actual usage.
} 
landscape for vineyards and orchards in Italy and their effects on irrigation water allocation and pricing. Their study finds that the amenity value per ha ranges from $\$ /$ ha 9 to 63 thousand. ${ }^{31}$ The reason for their relatively large range is twofold. First, they examine two crops (Vineyards and Orchards) which affect property values differently. Second, they sample five different regions that vary in area. An alternative approach is to divide the amenity value by the irrigated water consumption (513.3 MCM from Table 1). My figures result in \$/CM 12.1, while Thiene and Tsur (2013) report a range between $\$ / C M 5$ to 63 .

\section{Conclusion}

Until a decade ago, in Israel, water pricing and quotas were used for promoting landuse and settlement policies, food security and heritage preservation; water policy and agricultural production were interlinked through the administrative water allocation mechanism because irrigation water was a limiting factor of agricultural production. Through this mechanism, the public internalized both the tangible aspects (e.g., food production, landscape and habitat) and less tangible, non-use and cultural-heritage value. The model extends the household welfare and agricultural production functions to include agricultural amenities. By introducing a hypothetical pure water market, the agricultural amenity value is imputed by comparing the gains in economic welfare from the water market, with the lost social welfare from removing the administrative water allocation.

At the margin, the value of agricultural amenities that makes the household indifferent between the two mechanisms is imputed at 109\% of agricultural output. The inframarginal value is likely to be much higher because only the welfare distortions of the administrative mechanism were assessed, while additional value was omitted. These findings have relevance for developing policies to support the agricultural sector. Farmland is often undervalued due to the failure to account for the value of agricultural amenities. The loss of agricultural land to urbanization may be irreversible and costly to the well-being of society.

\footnotetext{
${ }^{31}$ Converted to US\$ with 1.3 per Euro, the average in 2012, around the time of its publication.
} 


\section{References}

Bar-Shira, Z., I. Finkelshtain, and A. Simhon: 2006, 'Block-Rate versus Uniform Water Pricing in Agriculture: An Empirical Analysis'. American Journal of Agricultural Economics 88(4), 986-999.

Bastian, C. T., D. M. McLeod, M. J. Germino, W. A. Reiners, and B. J. Blasko: 2002, 'Environmental amenities and agricultural land values: a hedonic model using geographic information systems data'. Ecological Economics 40(3), 337-349.

Baum, Z., R. R. Palatnik, I. Kan, and M. Rapaport-Rom: 2016, 'Economic Impacts of Water Scarcity Under Diverse Water Salinities'. Water Economics and Policy 02(01), 1550013.

Becker, N.: 1995, 'Value of moving from central planning to a market system: lessons from the Israeli water sector'. Agricultural Economics 12(1), 11-21.

Becker, N., D. Lavee, and T. Tavor: 2012, 'Desalinate or divert? Coastal non-market values as a decision tool for an integrated water management policy: The case of the Jordan River basin'. Ocean \& Coastal Management 64(Supplement C), 27-36.

Beltrán, M. J. and G. Kallis: 2018, 'How Does Virtual Water Flow in Palestine? A Political Ecology Analysis'. Ecological Economics 143, 17-26.

Bergstrom, J. C., B. Dillman, and J. R. Stoll: 1985, 'Public Environmental Amenity Benefits Of Private Land: The Case Of Prime Agricultural Land'. Southern Journal of Agricultural Economics 17(01).

Bergstrom, J. C. and R. C. Ready: 2009, 'What Have We Learned from over 20 Years of Farmland Amenity Valuation Research in North America?'. Review of Agricultural Economics 31(1), 21-49.

Borchers, A., J. Ifft, and T. Kuethe: 2014, 'Linking the Price of Agricultural Land to Use Values and Amenities'. American Journal of Agricultural Economics 96(5), 1307-1320.

Bowker, J. M. and D. Didychuk: 1994, 'Estimation of nonmarket benefits of agricultural land retention in eastern Canada'. Agricultural Resource Economics Review 23, 218-225.

Brunstad, R. J., I. Gaasland, and E. Vårdal: 1999, 'Agricultural Production and the Optimal Level of Landscape Preservation'. Land Economics 75(4), 538-546.

Chan, K. M. A., T. Satterfield, and J. Goldstein: 2012, 'Rethinking ecosystem services to better address and navigate cultural values'. Ecological Economics 74, 8-18. 
Davidovich, F. K.: 2008, 'Water Crisis in Israel - The Implementation of The Parliamentary Committee of Inquiry on the Israeli Water Sector and Sustainable Development'. Technical report, Knesset (Parliament), Israel, Center for Research and Information (Hebrew).

de Groot, R. S., M. A. Wilson, and R. M. J. Boumans: 2002, 'A typology for the classification, description and valuation of ecosystem functions, goods and services'. Ecological Economics 41(3), 393-408.

Diao, X., A. Dinar, T. Roe, and Y. Tsur: 2008, 'A general equilibrium analysis of conjunctive ground and surface water use with an application to Morocco'. Agricultural Economics 38(2), 117-135.

Diao, X. and T. Roe: 2003, 'Can a water market avert the "double-whammy" of trade reform and lead to a "win-win" outcome?'. Journal of Environmental Economics and Management 45(3), 708-723.

Dinar, A.: 2014, 'Water and Economy-Wide Policy Interventions'. Foundations and Trends $\mathbb{R}$ in Microeconomics 10(2), 85-165.

Drake, L.: 1992, 'The non-market value of the Swedish agricultural landscape'. European Review of Agricultural Economics 19(3), 351 -364.

Engel, S., S. Pagiola, and S. Wunder: 2008, 'Designing payments for environmental services in theory and practice: An overview of the issues'. Ecological Economics 65(4), 663-674.

Finkelshtain, I. and Y. Kislev: 1997, 'Prices versus Quantities: The Political Perspective'. Journal of Political Economy 105(1), 83-100.

Fleischer, A. and Y. Tsur: 2000, 'Measuring the recreational value of agricultural landscape'. European Review of Agricultural Economics 27(3), 385-398.

Fleischer, A. and Y. Tsur: 2003, 'Measuring the Recreational Value of Open Spaces'. Journal of Agricultural Economics 54, 269-283.

Fleischer, A. and Y. Tsur: 2009, 'The Amenity Value of Agricultural Landscape and Rural-Urban Land Allocation'. Journal of Agricultural Economics 60(1), 132-153.

Gómez, C. M., D. Tirado, and J. Rey-Maquieira: 2004, 'Water exchanges versus water works: Insights from a computable general equilibrium model for the Balearic Islands'. Water Resources Research 40, 11 PP.

Haaretz: 2014, 'Israel's desalination program averts future water crises'. Nature \& Environment, Haaretz (English). 
Hall, C., A. McVittie, and D. Moran: 2004, 'What does the public want from agriculture and the countryside? A review of evidence and methods'. Journal of Rural Studies 20(2), 211225.

Hassan, R. and J. Thurlow: 2011, 'Macro-micro feedback links of water management in South Africa: CGE analyses of selected policy regimes'. Agricultural Economics 42(2), 235-247.

Hertel, T. W.: 2002, 'Chapter 26 Applied general equilibrium analysis of agricultural and resource policies'. In: B. L. Gardner and G. C. Rausser (eds.): Agriculture and its External Linkages, Vol. Volume 2, Part 1 of Handbook of Agricultural Economics. Elsevier, pp. 13731419 .

Hosoe, N., K. Gasawa, and H. Hashimoto: 2010, Textbook of Computable General Equilibrium Modelling: Programming and Simulations. Palgrave Macmillan.

Just, R. E., S. Netanyahu, and J. K. Horowitz: 1997, 'The Political Economy of Domestic Water Allocation: The Cases of Israel and Jordan'. In: D. D. Parker and Y. Tsur (eds.): Decentralization and Coordination of Water Resource Management. Springer, 1 edition.

Kan, I., D. Haim, M. Rapaport-Rom, and M. Shechter: 2009, 'Environmental amenities and optimal agricultural land use: The case of Israel'. Ecological Economics 68(6), 1893-1898.

Kosoy, N. and E. Corbera: 2010, 'Payments for ecosystem services as commodity fetishism'. Ecological Economics 69(6), 1228-1236.

Luckmann, J., D. Flaig, H. Grethe, and K. Siddig: 2016, 'Modelling Sectorally Differentiated Water Prices - Water Preservation and Welfare Gains Through Price Reform?'. Water Resources Management 30(7), 2327-2342.

Luckmann, J., H. Grethe, S. McDonald, A. Orlov, and K. Siddig: 2014, 'An integrated economic model of multiple types and uses of water'. Water Resources Research 50(5), 3875-3892.

Menahem, G.: 1998, 'Policy Paradigms, Policy Networks and Water Policy in Israel'. Journal of Public Policy 18(3), 283-310.

Muñoz-Piña, C., A. Guevara, J. M. Torres, and J. Braña: 2008, 'Paying for the hydrological services of Mexico's forests: Analysis, negotiations and results'. Ecological Economics 65(4), $725-736$.

OECD: 2005, Financing Agricultural Policies with Particular Reference to Public Good Provision and Multifunctionality: Which Level of Government? Organisation for Economic Co-operation and Development. 
OECD: 2008, Multifunctionality in Agriculture: Evaluating the degree of jointness, policy implications. Organisation for Economic Co-operation and Development.

OECD: 2017, 'Agricultural Policy Monitoring and Evaluation 2017'. Technical report, OECD Publishing, Paris.

Oglethorpe, D. R. and D. Miliadou: 2000, 'Economic Valuation of the Non-use Attributes of a Wetland: A Case-study for Lake Kerkini'. Journal of Environmental Planning and Management 43, 755-767.

Parker, D. D. and Y. Tsur (eds.): 1997, Decentralization and Coordination of Water Resource Management. Springer Science \& Business Media.

Peterson, J. M., R. N. Boisvert, and H. de Gorter: 2002, 'Environmental policies for a multifunctional agricultural sector in open economies'. European Review of Agricultural Economics 29(4), $423-443$.

Reznik, A., E. Feinerman, I. Finkelshtain, I. Kan, F. Fisher, A. Huber-Lee, and B. Joyce: 2016, 'The Cost of Covering Costs: A Nationwide Model for Water Pricing'. Water Economics and Policy 02(04), 1650024.

Rinat, Z.: 2016, 'Israel Is Undisputed World Leader in Using Purified Wastewater for Crops'. Haaretz.

Rutherford, T. F.: 1995, 'Extension of GAMS for complementarity problems arising in applied economic analysis'. Journal of Economic Dynamics and Control 19(8), 1299-1324.

Rutherford, T. F.: 2002, 'Lecture Notes on Constant Elasticity Functions'.

Sánchez-Azofeifa, G. A., A. Pfaff, J. A. Robalino, and J. P. Boomhower: 2007, 'Costa Rica's payment for environmental services program: intention, implementation, and impact'. Conservation Biology: The Journal of the Society for Conservation Biology 21(5), 1165-1173.

Shemer, H. and R. Semiat: 2017, 'Sustainable RO desalination - Energy demand and environmental impact'. Desalination 424(Supplement C), 10-16.

Shoven, J. B. and J. Whalley: 1992, Applying General Equilibrium. Cambridge University Press.

Tal, A.: 2007, 'To Make a Desert Bloom: The Israeli Agricultural Adventure and the Quest for Sustainability'. Agricultural History 81(2), 228-257.

Thiene, M. and Y. Tsur: 2013, 'Agricultural Landscape Value and Irrigation Water Policy'. Journal of Agricultural Economics 64(3), 641-653. 
Vatn, A.: 2002, 'Multifunctional agriculture: some consequences for international trade regimes'. European Review of Agricultural Economics 29(3), 309-327.

Zhao, J., X. Cai, and Z. Wang: 2013, 'Comparing administered and market-based water allocation systems through a consistent agent-based modeling framework'. Journal of Environmental Management 123, 120-130. 


\section{Using Water Allocation in Israel as a Proxy for Imputing the Value of Agricultural Amenities}

Ecological Economics (2018)

Erez Yerushalmi, erez.yerushalmi@bcu.ac.uk

\section{A The model: further detail}

This is the supplementary appendix for the the paper "Using Water Allocation in Israel as a Proxy for Imputing the Value of Agricultural Amenities". This is a multisector, multi-water type, computable general equilibrium (CGE) model, that is coded in GAMS and MPSGE Rutherford $(1995,1999)$. It integrates a Monte Carlo method for sensitivity testing.

\section{A.1 Households and firms}

As discussed in Section 3.2 of the paper, the household utility maximization problem is:

$$
\begin{aligned}
& \max U\left(W P_{h}, C\left(X_{i}\right)\right)=\left[\beta^{\frac{1}{\sigma_{h}}} W P_{h}^{\frac{\sigma_{h}-1}{\sigma_{h}}}+(1-\beta)^{\frac{1}{\sigma_{h}}}\left[\prod_{i=1}^{z}\left\{X_{i}^{\theta_{i}}\right\}\right]^{\frac{\sigma_{h}-1}{\sigma_{h}}}\right]^{\frac{\sigma_{h}}{\sigma_{h}-1}} \\
& \text { s.t. } \sum_{i} p_{i} X_{i}+p_{W P, h} W P_{h}=p_{L} \bar{L}+\sum_{i} p_{K, i} \bar{K}_{i}+p_{K, w} \bar{K}_{w}+p_{a m e n} X_{a m e n}
\end{aligned}
$$

$\sigma_{h}$ is the substitution elasticity between potable water and the aggregate consumption of final goods, $\beta$ is a share parameter in the CES function, $\theta_{i}$ is the share exponents of the CD function for goods and amenity with $\sum_{i} \theta_{i}=1$. Note furthermore that $\theta_{\text {amen }} \in \theta_{i}$ is the share exponent of the amenity (i.e., when $\theta_{\text {amen }}=0$, no amenity is present).

To simplify the notation of standard mathematical equations, I summarize more complex nested functions in a non-mathematical form. For example, the two-level nested function from equation (A.1) could be simply written as $U=C E S\left[W P_{h}, C, \beta, \sigma_{h}\right]$ for the top-level, and $C=C D\left[X_{i}, \theta_{i}\right]$ for the lower level.

Firm $i$ 's profit maximization problem, but dropping subscript $i$ for simplicity, is: 


$$
\begin{aligned}
\max \quad & =p Y-p I N_{j}-p_{K} K-p_{L} L-p_{W P} W P-p_{W N P} W N P \\
\text { s.t. } \quad Y & \geq C E S\left[K, N K L, \alpha_{1}, \sigma_{1}\right] \\
N K L & \geq \min \left[I N_{j}, W L, \alpha_{2}\right] \\
W L & \geq C E S\left[L, W, \alpha_{3}, \sigma_{3}\right] \\
W & \geq C E S\left[W P, W N P, \alpha_{4}, \sigma_{4}\right]
\end{aligned}
$$

with $\alpha_{1}$ to $\alpha_{4}$ the share parameters of the first input, at each nested level, and $\sigma_{1}$ to $\sigma_{4}$ the substitution elasticity for the CES function. Note that $N K L$ in the second nest is a fixed-share Leontief function, which is a special case of a CES that has a substitution elasticity of zero. Recall furthermore that the agricultural sector also creates the byproduct agricultural amenities. See Equation (8) in the paper.

\section{A.2 GAMS/MPSGE code}

Below is the GAMS/MPSGE code for the most basic water model, with only one trade channel and without a government and international trade. This is useful for those who know the MPSGE language. All data in excel format can be obtain upon request. The MPSGE code for the full model, which includes also Monte-Carlo simulations, is available upon request.

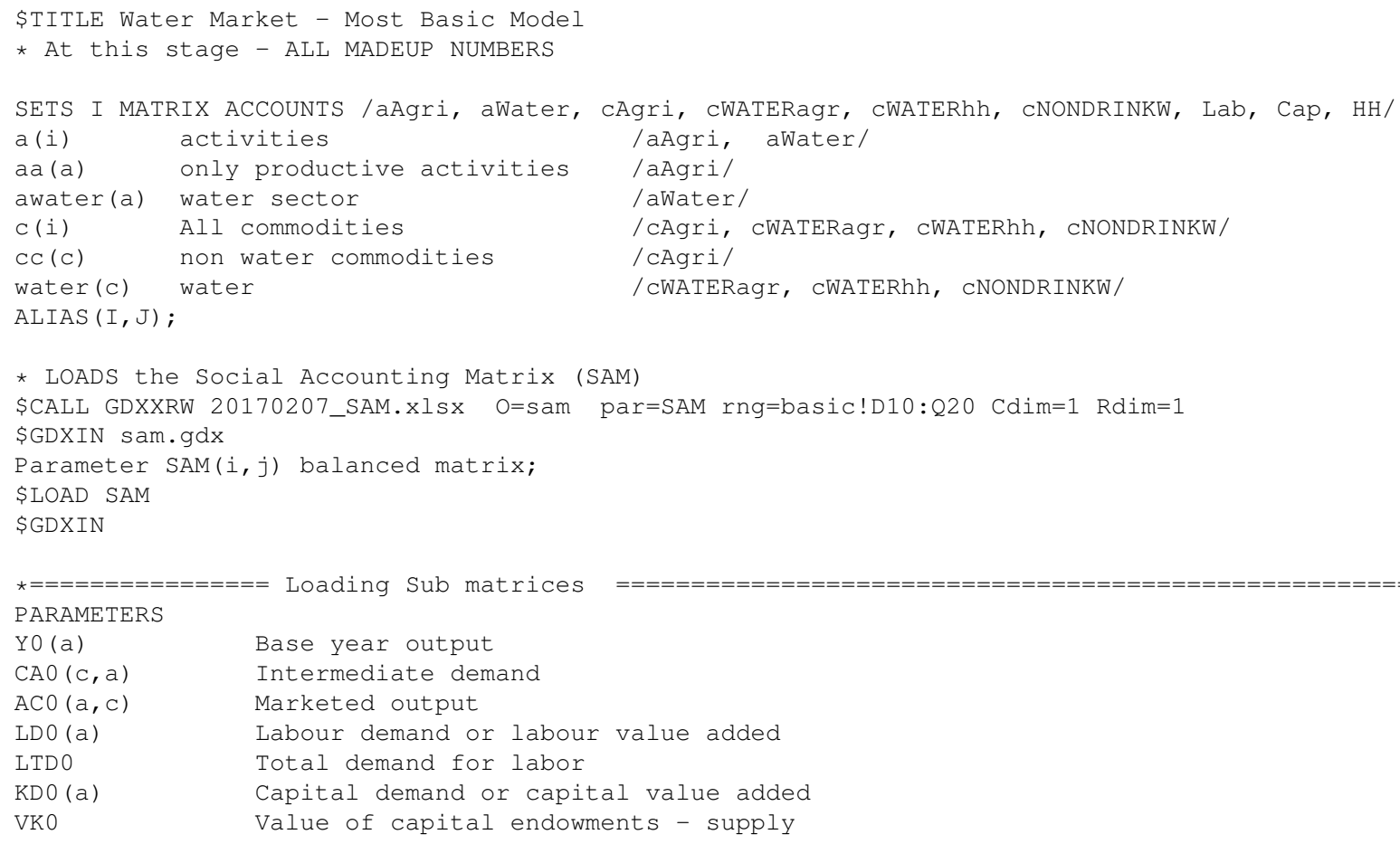




\section{E. Yerushalmi, Supplementary Content for on-line repository}

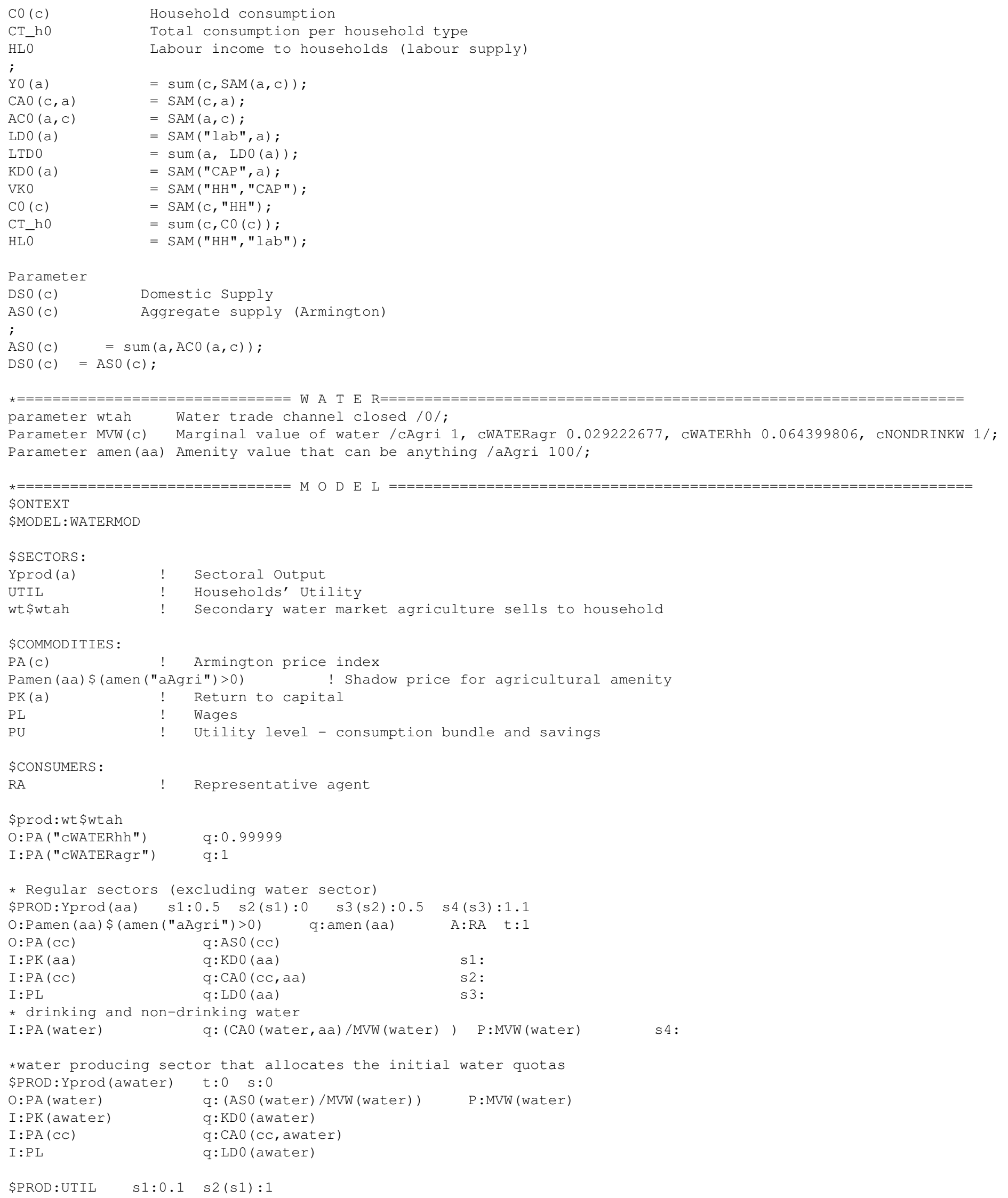




\section{E. Yerushalmi, Supplementary Content for on-line repository}

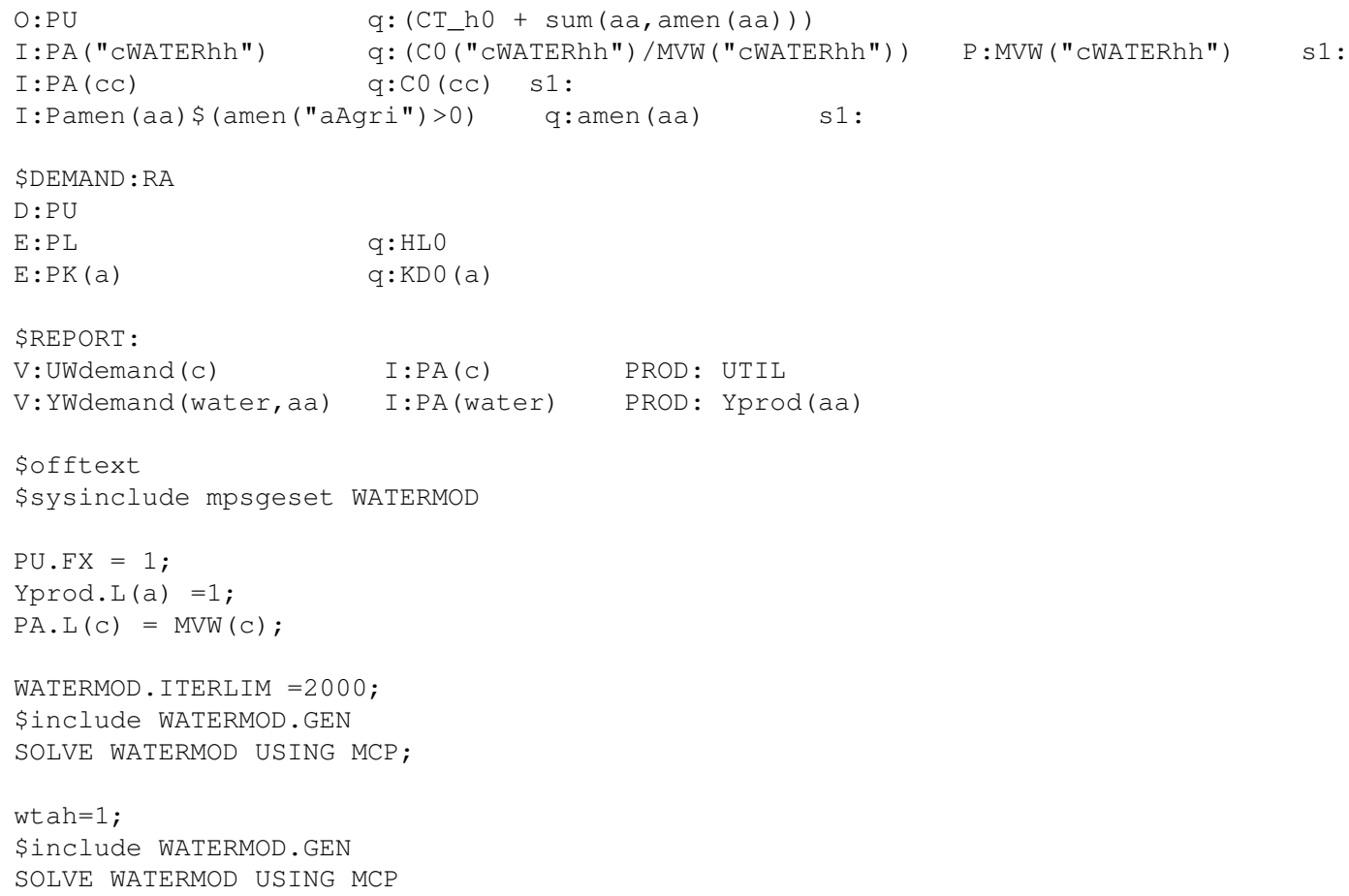

\section{B Approximating substitution elasticities in produc- tion and utility}

This section explains how the unknown substitution elasticities are calibrated at the various nested levels of production and utility. (For an overview of the nested structure, see Figures 1 and 2 in the paper).

There are many different options for structuring the nested functions, and therefore, there are no known substitution values. Rutherford (2002) and Shoven and Whalley (1992) generalize any nested-structure that combines key elasticities (demand and supply price) with the cost-shares from the SAM. Column 1 of Table 6 summarizes the sector-specific elasticities that are used in this paper. These are midvalues from the literature review from Israel and worldwide. Where possible, parameters from Israel were used. If none available, values from other countries were used. Combining these with the cost shares from the social accounting matrix (column 2), I obtain the calibrated substitution elasticities, $\sigma_{\text {level }_{i}}$, (column 3). Sections B.1 and B.2 document the precise formula. In addition, Section D explains in more detail how I use a Monte-Carlo method to simulate a distribution of the possible values in order to obtain a range of results.

Many empirical studies have estimated the supply price elasticity for the agricultural sector at around 0.8. (See Askari and Cummings (1977); Peterson (1988); 


\section{E. Yerushalmi, Supplementary Content for on-line repository}

Rao (1989) for a good review of the findings.) For manufacturing and service sectors, a great deal of literature focuses on supply price elasticities of single sectors, e.g., transport, housing, energy. To my knowledge, there are no aggregate level estimate as required here. ${ }^{32}$ Generally, however, supply price elasticities are elastic, and therefore set at 3 .

Water demand price elasticity, $\epsilon_{W, i}$, is reported in many empirical studies. For example, van Heerden et al. (2008) provide water demand elasticities for various sectors in a CGE model of South Africa. For the agricultural sector, in various countries, Bernardo et al. (1987); Booker and Young (1994); Moore and Hedges (1963); Nieswiadomy (1985); Scheierling et al. (2004) among many find find values ranging from -0.14 to -1 . For the Israeli agriculture sector, -0.7 is an accepted figure by researchers. For example, Eckstein (2001) estimates the agricultural demand price elasticities in Israel to be between -0.5 to -0.8, Bar-Shira et al. (2006) estimate a demand of - 0.46 , while Becker and Lavee (2002) state that it is closer to -1. For the manufacturing sector, Williams and Suh (1986) and Wang and Lall (2002) estimate the water demand price elasticities to be between -0.7 to -1 , while I use -0.7 .

Water demand price elasticities for households and service sectors, which are mainly office buildings within residential areas, are based on surveys for residential water demand. Hansen (1996); Arbués et al. (2003); Dalhuisen et al. (2003); Moeltner and Stoddard (2004) among others report values ranging between -0.1 and -0.3. Fishelson (1994); Bar-Shira et al. (2007); Dahan and Nisan (2007); Reznik et al. (2016) estimate the residential water demand in Israel at around -0.1 .

Finally, the substitution elasticity between potable and non-potable water, in the fourth-level, is assumed to be 1.1 for agriculture and 0.2 for manufacturing, based on the IWA.

\section{B.1 Production}

Production is structured as a four level production function, which was discussed in Equation (A.2) and Figure 2. In the top-level, an aggregator $N W L_{i}$ is combined with the immobile capital input. As Rutherford (2002, p.20) shows, for a function with one immobile input, the substitution elasticity $\sigma_{1, i}$ is calibrated by

$$
\sigma_{1, i}=\frac{\eta_{i} \theta_{K, i}}{1-\theta_{K, i}}
$$

\footnotetext{
${ }^{32}$ For example, literature that report for single sectors are Blackley (1999); Green et al. (2005); Malpezzi and Maclennan (2001) that find elastic values for the housing market, as high as 20. Dahl and Duggan (1996) reports a supply price elasticity of 1.27 in the U.S. energy market.
} 


\section{E. Yerushalmi, Supplementary Content for on-line repository}

Table 6: Calibrating the substitution elasticities, SAM 2006

\begin{tabular}{|c|c|c|c|c|c|c|c|c|c|c|}
\hline & \multicolumn{7}{|c|}{ Exogenous } & \multirow{2}{*}{\multicolumn{3}{|c|}{$\begin{array}{c}\text { Endogenous } \\
\text { Calibrated } \\
\text { Substitution } \\
\text { Elasticity }\end{array}$}} \\
\hline & $\begin{array}{c}\text { Output } \\
\text { Supply } \\
\text { Elasticity }^{a}\end{array}$ & $\begin{array}{c}\text { Water } \\
\text { Demand } \\
\text { Elasticity }^{a}\end{array}$ & $\begin{array}{c}\text { Potable/ } \\
\text { Non-Potable } \\
\text { substitution }\end{array}$ & SA & I Cost $\mathrm{S}$ & $\operatorname{tares}(2$ & $6, \%)^{c}$ & & & \\
\hline & $\eta_{i}$ & $\begin{array}{r}\epsilon_{W, i} \\
\quad(1)\end{array}$ & $\sigma_{4, i}$ & $\theta_{K, i}$ & $\theta_{W, 1, i}$ & $\theta_{W, 2, i}$ & $\theta_{W, 3, i}$ & $\sigma_{1, i}$ & $\begin{array}{l}\sigma_{2, i} \\
(3)\end{array}$ & $\sigma_{3, i}$ \\
\hline Agriculture & 0.8 & -0.7 & 1.1 & 19.7 & 4.5 & 5.6 & 15.0 & 0.20 & 0 & 0.82 \\
\hline Manufact. & 3.0 & -0.7 & 0.2 & 11.3 & 0.1 & 0.1 & 0.5 & 0.38 & 0 & 0.70 \\
\hline Services & 3.0 & -0.1 & 0.2 & 20.3 & 0.1 & 0.1 & 0.2 & 0.77 & 0 & 0.10 \\
\hline Household & & $\begin{array}{r}\epsilon_{W, h} \\
-0.1 \\
\end{array}$ & & & $\begin{array}{c}\theta_{W, h} \\
0.6 \\
\end{array}$ & & & $\begin{array}{c}\sigma_{1, h} \\
0.094 \\
\end{array}$ & & \\
\hline
\end{tabular}

Source: ${ }^{a}$ Approximate mid-values reported in various papers. ${ }^{b}$ Israel Water Authority. ${ }^{c}$ Cost shares are from the Social accounting Matrix. Source: Central Bureau of Statistics Israel.

Note: Calibrating substitution elasticities is done by combining the supply and demand elasticities with the cost shares following equations B.3 and B.4.

$\theta_{K, i}$ is the benchmark value cost share of the (immobile) capital, which is obtained from the social accounting matrix (SAM). $\eta_{i}$ is the supply price elasticity obtained from empirical studies.

In the second-level, it is common practice to aggregate intermediate inputs and sub-aggregates in fixed-proportions, $\sigma_{2, i}=0$, especially at a high macro-level.

Finally, in the third-level, water and labor inputs are combined, and their substitution elasticity $\sigma_{3, i}$ is calibrated by

$$
\sigma_{3, i}=\frac{\epsilon_{W, i}+\sigma_{2, i} \theta_{W, 3, i}-\left(\sigma_{2, i}-\sigma_{1, i}\right) \theta_{W, 2, i}-\sigma_{1, i} \theta_{W, 1, i}}{\left(\theta_{W, 3, i}-1\right)}
$$

with $\sigma_{1, i}$ and $\sigma_{2, i}$ being the elasticities from the upper levels. $\theta_{W, 1, i}, \theta_{W, 2, i}, \theta_{W, 3, i}$ are the water cost-shares relative to each nest, for the various sectors $i$, which are obtained from the SAM. The derivation of Equation (B.4) is documented below.

\section{B.1.1 Deriving equation B.4}

This method was outlined by Rutherford (2002) for any generalized nested-structure. Note that the second-level is known and assumed to be a Leontief function, which is a special case of a CES function that uses a substitution elasticity of zero. The fourth-level is aggregated into the third.

If I construct the cost function from a calibrated benchmark in which input prices and total cost are unity, I can scale the benchmark values of the sub-aggregate cost 


\section{E. Yerushalmi, Supplementary Content for on-line repository}

as unity and express the demand for water as

$$
W=\left[p_{W}\right]^{-\sigma_{3}} p_{W L}^{\sigma_{3}-\sigma_{2}} p_{N W L}^{\sigma_{2}-\sigma_{1}}\left[p_{Y}\right]^{\sigma_{1}} \bar{W}
$$

The derivative of the the demand for water with respect to the input price of water, at the initial allocation point where all prices are unity is

$$
\left.\frac{\partial W}{\partial p_{W}}\right|_{p=1}=\left[-\sigma_{3}+\left(\sigma_{3}-\sigma_{2}\right) \frac{\partial p_{W L}}{\partial p_{W}}+\left(\sigma_{2}-\sigma_{1}\right) \frac{\partial p_{N W L}}{\partial p_{W}}+\sigma_{1} \frac{\partial p_{Y}}{\partial p_{W}}\right] \bar{W}
$$

By Shephard's Lemma, the derivative of the unit cost function with respect to input prices, leads to the share of inputs at the benchmark calibration, as follows

$$
\begin{gathered}
\frac{\partial p_{W L}}{\partial p_{W}}=\frac{p_{W} \bar{W}}{p_{W} \bar{W}+p_{L} \bar{L}}=\theta_{W, 3} \\
\frac{\partial p_{N W L}}{\partial p_{W}}=\frac{p_{W} \bar{W}}{p_{W} \bar{W}+p_{L} \bar{L}+p_{N} \bar{N}}=\theta_{W, 2} \\
\frac{\partial p_{Y}}{\partial p_{W}}=\frac{p_{W} \bar{W}}{p_{W} \bar{W}+p_{L} \bar{L}+p_{N} \bar{N}+p_{K} \bar{K}}=\frac{p_{W} \bar{W}}{p_{Y} \bar{Y}}=\theta_{W, 1}
\end{gathered}
$$

where an over-bar, $\bar{\square}$, indicates values at the benchmark.

Combining the above with Equation (B.5), obtain

$$
\left.\frac{\partial W}{\partial p_{W}}\right|_{p=1}=\left[-\sigma_{3}+\left(\sigma_{3}-\sigma_{2}\right) \theta_{W, 3}+\left(\sigma_{2}-\sigma_{1}\right) \theta_{W, 2}+\sigma_{1} \theta_{W, 1}\right] \bar{W}
$$

Define the elasticity of demand as $\left.\epsilon_{W}\right|_{p=1}=\frac{\partial W}{\partial p_{W}} \frac{p_{W}}{W}$, and therefore

$$
\left.\epsilon_{W}\right|_{p=1}=\left[-\sigma_{3}+\left(\sigma_{3}-\sigma_{2}\right) \theta_{W, 3}+\left(\sigma_{2}-\sigma_{1}\right) \theta_{W, 2}+\sigma_{1} \theta_{W, 1}\right]
$$

Finally, solving for for $\sigma_{3}$ yields

$$
\sigma_{3}=\frac{\epsilon_{W}+\sigma_{2} \theta_{W, 3}-\left(\sigma_{2}-\sigma_{1}\right) \theta_{W, 2}-\sigma_{1} \theta_{W, 1}}{\left(\theta_{W, 3}-1\right)}
$$

\section{B.2 Household utility}

As shown by Shoven and Whalley (1992) and used in many other applications (e.g., see Borger et al. (2008)), the the first-level substitution elasticity $\sigma_{1, h}$ between water and the consumption bundle can be approximated by a function of the compensated water demand price elasticities $\epsilon_{w, h}$ and the cost share of water $\theta_{w, h}$ (obtained from 


\section{E. Yerushalmi, Supplementary Content for on-line repository}

the SAM):

$$
\sigma_{1, h}=\frac{\epsilon_{w, h}}{\theta_{w, h}-1}
$$

Interestingly, because the water cost share is nearly zero, the substitution elasticity equals minus the demand elasticity of water (see column 3 of Table 6). Finally, in the second-level, final goods are aggregated using a Cobb-Douglas function with $\sigma_{2, h}=1$, which is standard practice in many applied general equilibrium models. Equation (B.6) is derived in the following section.

\section{B.2.1 Deriving equation B.6}

Similar to Section B.1.1, the household substitution elasticity is calibrated using water demand price elasticities. At the calibrated benchmark, in which input prices and total expenditure are unity, we can scale the benchmark values of the sub-aggregate expenditure as unity and express the demand for household water as

$$
W_{h}=\bar{W}_{h} p_{W, h}^{-\sigma_{1, h}} p_{U}^{\sigma_{1, h}}
$$

where $p_{U}$ is defined as the expenditure function for a unit utility.

Differentiate the above with respect to household water expenditure, and obtain

$$
\frac{\partial W_{h}}{\partial p_{W, h}}=\bar{W}_{h}\left[-\sigma_{1, h} p_{W, h}^{-\sigma_{1, h}-1}+\sigma_{1, h} p_{U}^{\sigma_{1, h}-1} \frac{\partial p_{U}}{\partial p_{W, h}}\right]
$$

Again by Shephard's Lemma, the derivative of the unit expenditure function with respect to input prices will lead to the share of inputs at the benchmark calibration.

$$
\frac{\partial p_{U}}{\partial p_{W, h}}=\frac{p_{W, h} \bar{W}_{h}}{p_{W, h} \bar{W}_{h}+p_{C} \bar{C}}=\theta_{W, h}
$$

Recalling that all prices are unity at benchmark, rearrange Equation B.7 as:

$$
\left.\frac{\partial W_{h}}{\partial p_{W, h}}\right|_{p=1}=\bar{W}_{h}\left[-\sigma_{1, h}+\sigma_{1, h} \theta_{W, h}\right]
$$

Finally, defining the compensated own-price elasticity of household water demand as $\epsilon_{W, h}$, and solving for $\sigma_{1, h}$, obtain

$$
\sigma_{1, h}=\frac{\epsilon_{W, h}}{\theta_{W, h}-1}
$$


E. Yerushalmi, Supplementary Content for on-line repository

\section{Israel Water SAM (2006 NIS mln)}

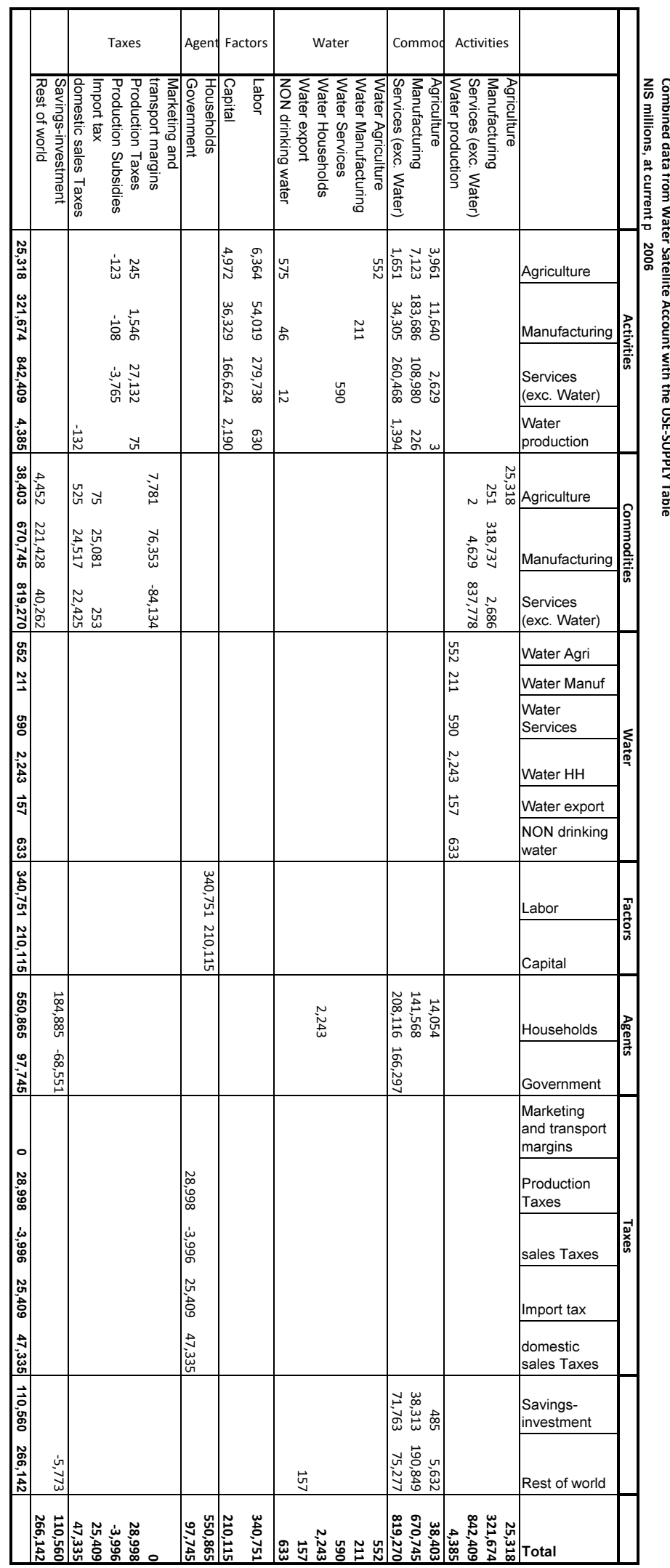




\section{E. Yerushalmi, Supplementary Content for on-line repository}

\section{Monte Carlo Simulations}

I use a Monte Carlo method to randomly generate a group of elasticities that jointly enter into the model. Column 2 in Table 3 provides the probability density function (PDF) assigned with the lower and upper parameters from column 1. These PDFs are based on the notional characteristics provided by empirical literature. The model is then executed 30,000 for section 5.1 and 100,000 times for section 5.2, and results are collected and analyzed. The code used for sampling in GAMS can be provided upon request.

Table 3 provided the probability density functions which were used to sample the various elasticities. For a beta distribution defined on the interval $[a, b]$ with the parameters $[\alpha, \beta]$ Figures 6 to 8 plot the sampled output supply price elasticities $\eta$, and Figures 9 to 12 plot the sampled water demand price elasticities $\epsilon$. Finally, Figure 13 plots the uniform density function sampled for the value of amenities.

Figure 6: $\eta$ Agriculture

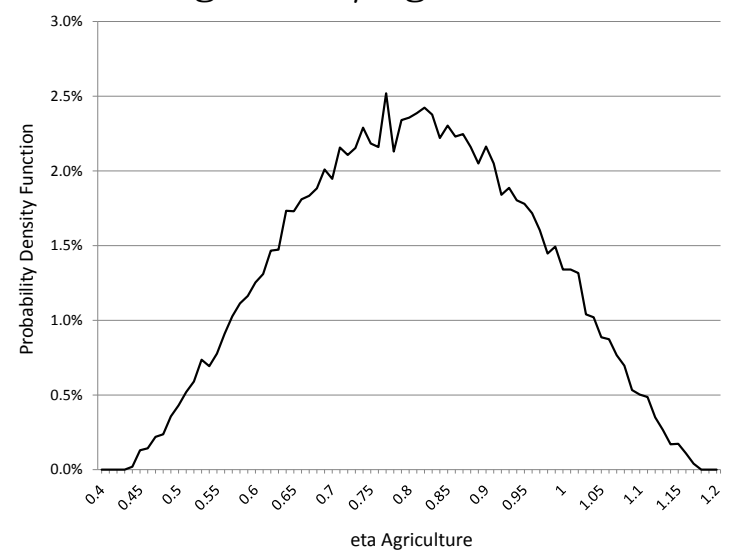

Figure 8: $\eta$ Services

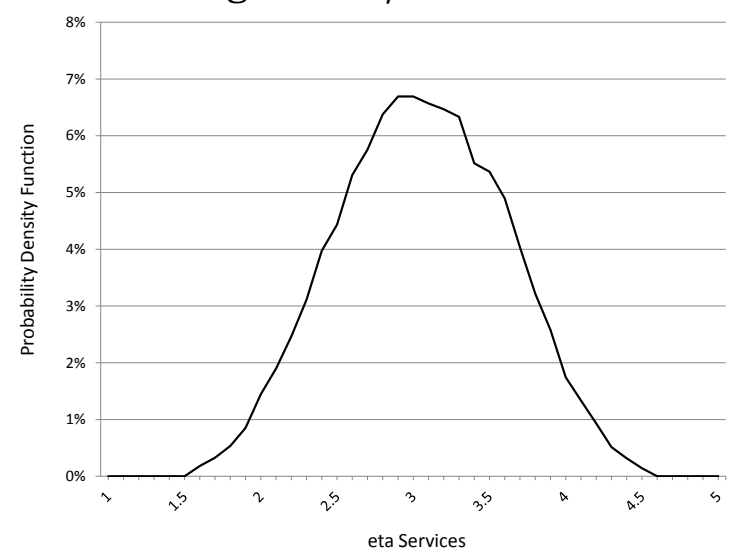

Figure 7: $\eta$ Manufacturing

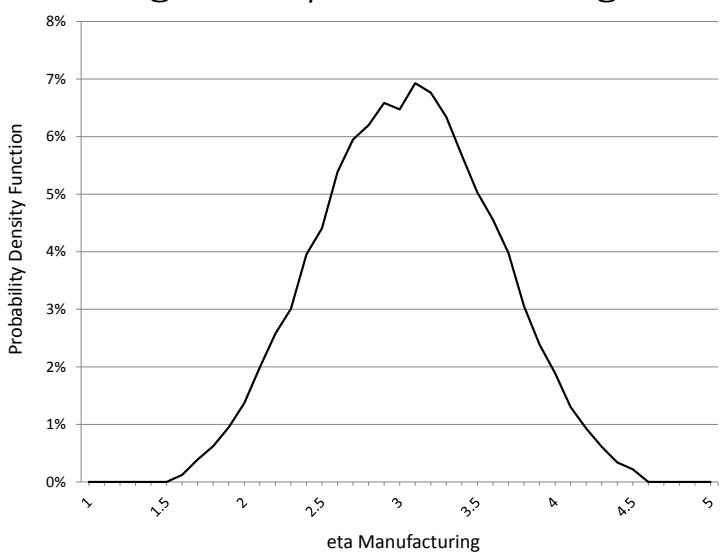

Figure 9: $\epsilon$ Household

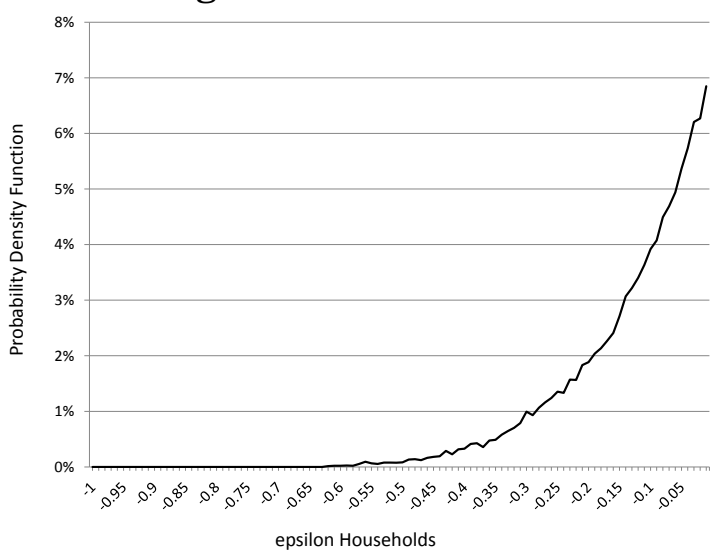


E. Yerushalmi, Supplementary Content for on-line repository

Figure 10: $\epsilon$ Agriculture

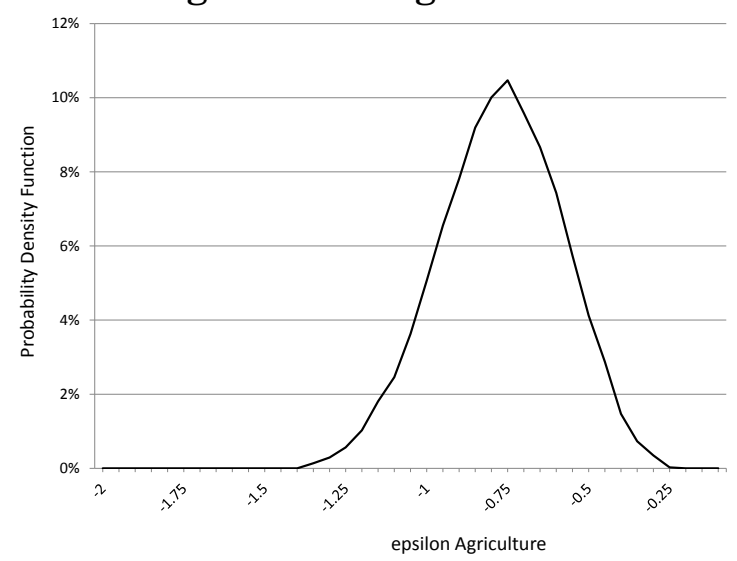

Figure 12: $\epsilon$ Services

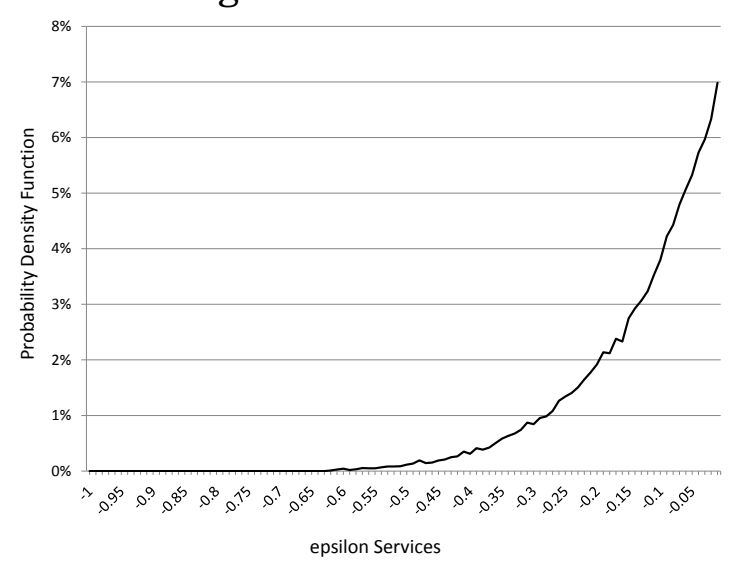

Figure 11: $\epsilon$ Manufacturing

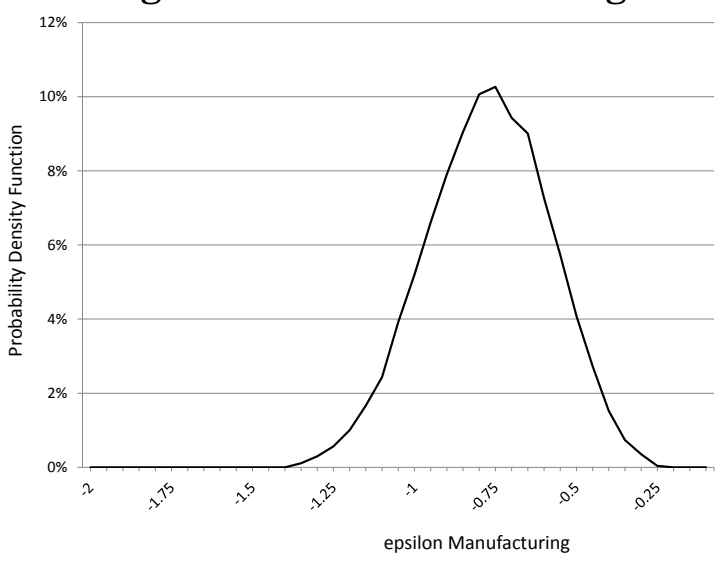

Figure 13: Value of amenities

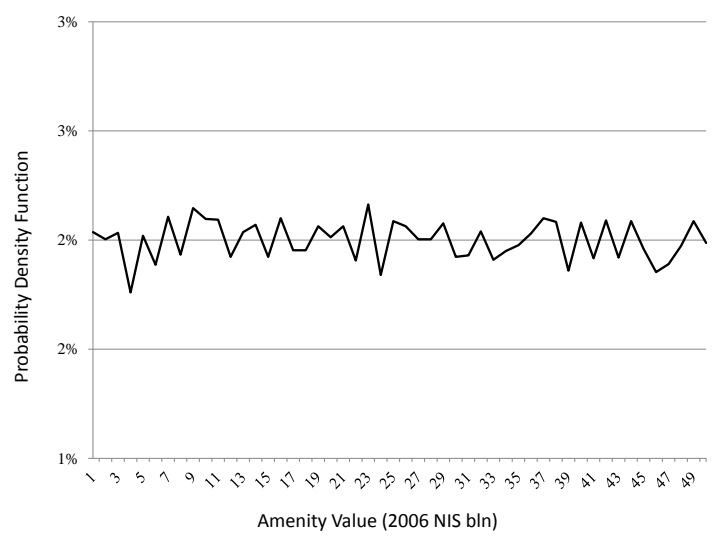




\section{E. Yerushalmi, Supplementary Content for on-line repository}

\section{E References for the on-line supplementary appendix}

Arbués, F., M. Ángeles García-Valiñas, and R. Martínez-Espiñeira: 2003, 'Estimation of residential water demand: a state-of-the-art review'. Journal of Socio-Economics 32(1), 81-102.

Askari, H. and J. T. Cummings: 1977, 'Estimating Agricultural Supply Response with the Nerlove Model: A Survey'. International Economic Review 18(2), 257-292.

Bar-Shira, Z., I. Finkelshtain, and A. Simhon: 2006, 'Block-Rate versus Uniform Water Pricing in Agriculture: An Empirical Analysis'. American Journal of Agricultural Economics 88(4), 986-999.

Bar-Shira, Z., Y. Kislev, and N. Cohen: 2007, 'The Demand for Water in the Municipalities'. The Economic Quarterly (54), 179-203.

Becker, N. and D. Lavee: 2002, 'The Effect and Reform of Water Pricing: The Israeli Experience'. International Journal of Water Resources Development 18(2), 353-366.

Bernardo, D. J., N. K. Whittlesey, K. E. Saxton, and D. L. Bassett: 1987, 'An Irrigation Model For Management Of Limited Water Supplies'. Western Journal of Agricultural Economics 12(02).

Blackley, D. M.: 1999, 'The Long-Run Elasticity of New Housing Supply in the United States: Empirical Evidence for 1950 to 1994'. The Journal of Real Estate Finance and Economics 18(1), 25-42.

Booker, J. F. and R. A. Young: 1994, 'Modeling Intrastate and Interstate Markets for Colorado River Water Resources'. Journal of Environmental Economics and Management 26(1), 66-87.

Borger, C., T. F. Rutherford, and G. Y. Won: 2008, 'Projecting long term medical spending growth'. Journal of Health Economics 27(1), 69-88.

Dahan, M. and U. Nisan: 2007, 'Unintended consequences of increasing block tariffs pricing policy in urban water'. Water Resources Research 43(3), W03402.

Dahl, C. and T. E. Duggan: 1996, 'U.S. energy product supply elasticities: A survey and application to the U.S. oil market'. Resource and Energy Economics 18(3), 243263. 


\section{E. Yerushalmi, Supplementary Content for on-line repository}

Dalhuisen, J. M., R. J. G. M. Florax, H. L. F. de Groot, and P. Nijkamp: 2003, 'Price and Income Elasticities of Residential Water Demand: A Meta-Analysis'. Land Economics 79(2), 292-308.

Eckstein, Z.: 2001, 'Is Water Desalination Necessary?'. In: A. Tal (ed.): The Water System, Studies and Opinions, The Interdisciplinary Center for Technological Analysis and Forecasting. Tel Aviv University, Tel Aviv, Israel: .

Fishelson, G.: 1994, 'The water market in Israel: An example for increasing the supply'. Resource and Energy Economics 16(4), 321-334.

Green, R. K., S. Malpezzi, and S. K. Mayo: 2005, 'Metropolitan-Specific Estimates of the Price Elasticity of Supply of Housing, and Their Sources'. The American Economic Review 95(2), 334-339.

Hansen, L. G.: 1996, 'Water and Energy Price Impacts on Residential Water Demand in Copenhagen'. Land Economics 72(1), 66-79.

Malpezzi, S. and D. Maclennan: 2001, 'The Long-Run Price Elasticity of Supply of New Residential Construction in the United States and the United Kingdom'. Journal of Housing Economics 10(3), 278-306.

Moeltner, K. and S. Stoddard: 2004, 'A panel data analysis of commercial customers' water price responsiveness under block rates'. Water Resources Research 40(1), W01401.

Moore, C. and T. Hedges: 1963, 'Economics of On-Farm Water Availability and Costs and Related Farm Adjustments'. Giannini Foundation Research Repor 263, University of California- Davis.

Nieswiadomy, M.: 1985, 'The Demand for Irrigation Water in the High Plains of Texas, 1957-80'. American Journal of Agricultural Economics 67(3), 619-626.

Peterson, W.: 1988, 'International supply response'. Agricultural Economics 2(4), $365-374$.

Rao, J. M.: 1989, 'Agricultural supply response: A survey'. Agricultural Economics 3(1), 1-22.

Reznik, A., E. Feinerman, I. Finkelshtain, I. Kan, F. Fisher, A. Huber-Lee, and B. Joyce: 2016, 'The Cost of Covering Costs: A Nationwide Model for Water Pricing'. Water Economics and Policy 02(04), 1650024. 


\section{E. Yerushalmi, Supplementary Content for on-line repository}

Rutherford, T. F.: 1995, 'Extension of GAMS for complementarity problems arising in applied economic analysis'. Journal of Economic Dynamics and Control 19(8), $1299-1324$.

Rutherford, T. F.: 1999, 'Applied General Equilibrium Modeling with MPSGE as a GAMS Subsystem: An Overview of the Modeling Framework and Syntax'. Computational Economics 14, 1-46.

Rutherford, T. F.: 2002, 'Lecture Notes on Constant Elasticity Functions'.

Scheierling, S. M., J. B. Loomis, and R. A. Young: 2004, 'Irrigation Water Demand: A Meta Analysis of Price Elasticities'. Technical report, Denver CO, Selected Paper prepared for presentation at the American Agricultural Economics Association Annual Meeting.

Shoven, J. B. and J. Whalley: 1992, Applying General Equilibrium. Cambridge University Press.

van Heerden, J. H., J. Blignaut, and M. Horridge: 2008, 'Integrated water and economic modelling of the impacts of water market instruments on the South African economy'. Ecological Economics 66(1), 105-116.

Wang, H. and S. Lall: 2002, 'Valuing water for Chinese industries: a marginal productivity analysis'. Applied Economics 34(6), 759.

Williams, M. and B. Suh: 1986, 'The Demand for Urban Water by Customer Class'. Applied Economics 18(12), 1275-1289. 